\title{
A scoping review of health-related stigma outcomes for high-burden diseases in low- and middle-income countries
}

\author{
Jeremy C. Kane ${ }^{1 *} \mathbb{D}$, Melissa A. Elafros², Sarah M. Murray', Ellen M. H. Mitchell, Jura L. Augustinavicius',
} Sara Causevic ${ }^{4}$ and Stefan D. Baral ${ }^{5}$

\begin{abstract}
Background: Stigma is associated with health conditions that drive disease burden in low- and middle-income countries (LMICs), including HIV, tuberculosis, mental health problems, epilepsy, and substance use disorders. However, the literature discussing the relationship between stigma and health outcomes is largely fragmented within diseasespecific siloes, thus limiting the identification of common moderators or mechanisms through which stigma potentiates adverse health outcomes as well as the development of broadly relevant stigma mitigation interventions.

Methods: We conducted a scoping review to provide a critical overview of the breadth of research on stigma for each of the five aforementioned conditions in LMICs, including their methodological strengths and limitations.

Results: Across the range of diseases and disorders studied, stigma is associated with poor health outcomes, including help- and treatment-seeking behaviors. Common methodological limitations include a lack of prospective studies, nonrepresentative samples resulting in limited generalizability, and a dearth of data on mediators and moderators of the relationship between stigma and health outcomes.
\end{abstract}

Conclusions: Implementing effective stigma mitigation interventions at scale necessitates transdisciplinary longitudinal studies that examine how stigma potentiates the risk for adverse outcomes for high-burden health conditions in community-based samples in LMICs.

Keywords: Stigma, Low- and middle-income countries, HIV, Tuberculosis, Epilepsy, Depression, Substance use, Scoping review

\section{Background}

Stigma is a major social determinant of health that drives morbidity, mortality, and health disparities [1], and has been described by the World Health Organization as a 'hidden' burden of disease [2]. Stigma is characterized by cognitive, emotional, and behavioral components and can be reflected both in the attitudes, often conceptualized as perceived, anticipated, or internalized stigmas, and experiences, including enacted or experienced stigmas affecting a particular trait, among individuals [3-5]. Perceived stigma refers to a person's understanding of how others may act towards, and think

\footnotetext{
* Correspondence: jkane29@jhu.edu

${ }^{1}$ Department of Mental Health, Johns Hopkins Bloomberg School of Public Health, 624 North Broadway, Baltimore, MD 21205, USA

Full list of author information is available at the end of the article
}

or feel about, an individual with a certain trait or identity [6]. Anticipated stigma refers to expectations of stigma experiences happening in the future [7]. Internalized stigma refers to the individual level process of awareness, acceptance, and application of stigma (to oneself) [8-10]. Finally, experienced or enacted stigma refers to discriminatory acts or behaviors [11].

Stigma adversely impacts individual health outcomes as well as related 'life chances', including educational opportunities, employment, housing, and social relationships [1]. It has also been shown to negatively affect help- and treatment-seeking behaviors, hindering the ability of public health agencies to treat and prevent stigmatized health conditions [12]. HIV-related stigma, in particular, has been cited as one of the most enduring barriers to ending the HIV pandemic [13, 14]. Yet, while HIV-related stigma has

(c) The Author(s). 2019 Open Access This article is distributed under the terms of the Creative Commons Attribution 4.0 International License (http://creativecommons.org/licenses/by/4.0/), which permits unrestricted use, distribution, and 
received greater attention, tuberculosis (TB), mental, neurological, and substance use disorders are also highly stigmatized drivers of the global burden of disease, with significant unmet treatment needs in low- and middle-income countries (LMICs) [15-20].

Hatzenbuehler et al. [1] argued that research on stigma and health outcomes is inappropriately siloed within specific disease/disorder domains. Across health disciplines, this separation has limited the ability to understand the overall impact of stigma on individual wellbeing and on global disease burden [1]. Research siloes have also restricted our ability to develop interventions addressing stigma, particularly in LMICs and among at-risk populations (e.g., lesbian, gay, bisexual, transgender, queer populations (LGBTQ); racial/ethnic minorities; refugees) for whom effective interventions are needed. Despite considerable progress in stigma research over the past decade, a critical review of the literature on the consequences of stigma across health conditions has not been undertaken.

This paper presents a scoping review of the literature on the health consequences of stigma at both the individual and healthcare system levels in LMICs. The review focuses on the main drivers of disease burden in LMICs, namely HIV, TB, mental health, epilepsy, and substance use. The purpose is to summarize recent research on the association between stigma and these conditions, including the direct impact of stigma on affected individuals and its indirect impact on health systems according to help-seeking behavior or service utilization. In so doing, this review highlights commonalities across conditions as well as the key mediators and moderators of the relationship between stigma and health, and identifies at-risk and vulnerable groups. Finally, the strengths and limitations of the current state-of-the-science are highlighted, and recommendations are made for future studies measuring the health-related outcomes of stigma, their pathways, and approaches for evidence-based interventions in LMICs.

\section{Methods}

\section{Search strategy, data charting, and data summary}

We conducted a scoping literature review [21] to summarize current research on stigma and health in relation to five high-burden conditions in LMICs, highlighting the gaps and informing future directions [22]. Five searches of peer-reviewed manuscripts published between 2008 and 2017 were conducted between November 2017 and February 2018 using the PubMed (MEDLINE), PsychINFO, and EMBASE databases. Searches included terms related to (1) 'stigma' or other associated terms such as 'discrimination'; (2) 'LMICs', including all countries with this classification according to the World Bank; and (3) specific diseases or disorders.
Epilepsy was selected to represent neurologic disorders due to the lack of stigma data related to other neurologic conditions. Additional file 1 includes the full list of search terms for each database searched.

Each review and synthesis was conducted by a single study author with condition-specific expertise. An initial title and abstract review was performed, followed by full-text review of any article included during the first phase. For charting, data were extracted according to study authors and year of publication, study design, sample size and sampling characteristics, type of stigma measured (i.e., perceived, anticipated, internalized, experienced/enacted), strength and significance, if applicable, of the stigma and health outcome association, and mediators or moderators.

In reviewing stigma related to the five diseases/disorders assessed, our team identified three populations most adversely affected by stigma, namely LGBTQ individuals, racial and ethnic minorities, and refugees. Boxes 1,2 and 3 present further details on the relationship between stigma and health for these populations, focusing on commonalities across disorders.

\section{Box 1. Population of concern: LGBTQ}

A study done among transgender female sex workers in China reveals limited access to services due to amplified stigma because of their gender identity and their profession [230]. Thus, many decide to engage in self-medication, especially for the transitioning phase, including self-administering hormone use. A case study exploring the economic costs of stigma in India indicates different reasons; if discussing LGBTQ, it is the fear of family deprecation, professional discrimination, and overall societal rejection, yet healthcare providers confidentiality can also lead to discrimination, ultimately leading to breach of human rights [231]. All of them could potentially lead to adverse sexual health outcomes, suicide, and depression. A study performed in Vietnam [232], as a part of a case study series on researching LGBTQ in Asia, found that due to the stigma around the transgender society, transgender people end up doing their own research on gender-confirmation surgery or self-inject cheap and impure chemicals such as silicone and other petroleum products, which in some cases lead to serious harm and even fatalities. The same case study series, with findings from Nepal [233], reported that LGBTQ encounter stigma on daily basis from an early age, shaping how they perceive and interact with all aspects of society, including healthcare. The vast number of institutions, including those in Nepal, stigmatize gender and sexual minorities, with important implications for the ability of healthcare providers and institutions to address their health needs [233]: 


\section{Box 2. Population of concern: Racial and ethnic minorities}

Qualitative studies with refugee, asylum seeking, and immigrant new mothers [234] with depressive symptoms seeking mental health services, including a study with Korean American immigrant women [235], showed a challenging path to recovery due to social isolation and perceived stigma. A study that explored depression and care among Asian Indians in the USA collected data from interviews of 23 multidisciplinary mental health professionals and retrospective review of 20 medical records of patients [236]. Findings revealed that that social stigma contributed to the prolonged denial of a condition, difficulty in communicating the problem, and delayed professional intervention in those suffering from depression. People living with HIV are stigmatized and looked at negatively, with the fear of discrimination preventing patients from accessing care and the stigma remains a barrier to effectively addressing the disease [237]. Immigrant HIV-positive Latina women in the Midwest USA experienced feelings of stigma, leading to depression, rejection, or suicidal attempts; few had received any type of mental health care intervention [238]. Few cases of self-imposed stigma or 'self-stigma' as a result of minority status has led to reduced health-seeking behavior from health professionals due to fear that disclosing the minority status might be an obstacle from receiving care [239]. Similar findings were presented as part of a qualitative study in mental health among Asian communities in Australia and the unwillingness to access help from healthcare services due to stigma and shame [240]. Immigration and transmission of tuberculosis were reinforcing each other's stigma [241].

\section{Results}

\section{Characteristics of included studies}

The database search identified a total of 186 articles discussing one or more of the defined diseases and their relationship with stigma, including 59 articles on HIV (32\%), 29 on TB (16\%), 27 on mental health (14\%), 25 on epilepsy (13\%), and 46 on substance use (25\%) (Fig. 1). Across studies, 52 LMICs were represented, with 79 studies (43\%) focusing on Asia, 70 (38\%) on Africa, 21 (11\%) on South and Central America, 10 (5\%) on Eastern Europe and Russia, and $6(3 \%)$ that included more than one region. The most frequently included countries were China $(n=30)$, India $(n=21)$, and South Africa $(n=19)$. Over half of all included studies were published in 2015 or later, with more publications in 2017 than in any other year, suggesting that research attention to stigma is growing (Fig. 2).

\section{Box 3. Population of concern: Refugees}

Tibetan refugees in Nepal faced different layers of barriers, behavioral norms, and institutional structures that impair the diffusion of relevant information, creating a challenge to develop a comprehensive understanding of HIV/AIDS [242]. The stigma in both host and their own societies was hindering the individual's willingness to discuss the issue with their peers and with medical professionals [242]. A case study based on a literature review and semi-structured interviews of urban refugees in Egypt at high risk for HIV/AIDS [243] revealed that intense stigma and discrimination, vulnerability, and social stability resulted in a lack of adequate health resources and a chain of causation that marginalized refugees in Egyptian society. These social processes result in unequal access to health resources, thereby increasing their potential exposure to HIV transmission. The sexual violence being used as a weapon of war during conflicts (conflict-related sexual violence) has caused significant trauma in both women and men survivors. The experience of refugees in Ethiopia shows that the stigma associated with conflict-related sexual violence makes it challenging for the survivors to mitigate the potential long-term physical, mental, reproductive health, and social consequences [244].

Internalized stigma was the most common stigma type measured ( $44 \%$ of studies), whereas fewer studies focused on experienced (enacted), anticipated, or perceived stigma. Children and adolescents were underrepresented in the included studies, with less than $5 \%$ of the included studies involving youth populations. Cross-sectional (68\%) and qualitative (15\%) study designs were most common, and only $9 \%$ of studies used longitudinal data.

Herein, a summary of the reviews for each disease/ disorder is provided (Tables 1, 2, 3, 4 and 5), followed by a discussion on the overlap and intersection of these stigmas.

\section{HIV}

Among people with HIV, both internalized and experienced stigma have been associated with increased prevalence of HIV-related symptoms and poorer self-reported health [23-26] (Table 1). Internalized and experienced HIV-related stigma have been associated with increased prevalence of mental health disorders [27-29], particularly depression [30-40] and anxiety [41, 42]. For example, among Nigerians with HIV [43], stigma was associated with a diagnosis of severe depression, although it was not associated with mild or moderately severe depression. Among Tanzanian youth [28] and South African adults [28, 36], post-traumatic stress 

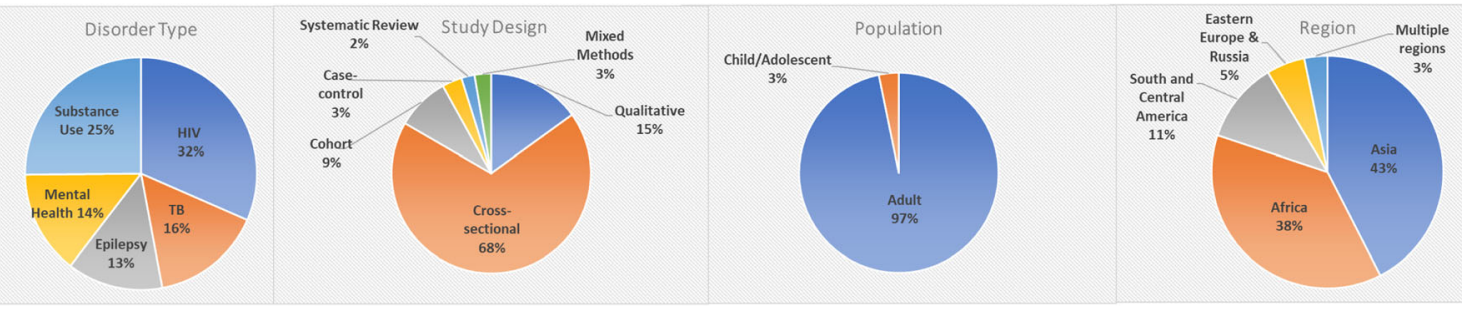

Fig. 1 Characteristics of included studies

disorder was also more common among those with high levels of internalized stigma. All forms of stigma have been associated with decreased resilience and self-esteem among Chinese adults [32].

HIV-related stigma has been linked to poor health behaviors. Anticipated, experienced, and internalized stigma have been repeatedly associated with decreased voluntary HIV testing and disclosure of infection [24, 44-49]. For example, among Tanzanian adults obtaining HIV services [50], internalized stigma has been linked to increased denial of HIV infection. HIV-positive individuals who report experienced (enacted) stigma are more likely to delay initiation or continuation of HIV care [25, 51, 52]. Those who experience stigma in a healthcare setting are also less likely to initiate antiretroviral therapy [25]. Available cohort data suggests that perceived stigma is associated with poor medication adherence according to participant reports and chart reviews [53-55]. A longitudinal cohort study of adults living with HIV in South Africa revealed that internalized stigma was associated with a greater incidence of condomless sex with both HIV-negative/unknown and HIV-positive partners [5]. Finally, stigma has been associated with increases in smoking, alcohol, and drug use [32], as well as with suicidal ideation and attempted suicide [56, 57].
Significant mediators of the relationships between HIV-related stigma and health outcomes included individual resilience [23], depression, negative condom use attitudes [5], and self-efficacy [58]. While most data demonstrated an inverse relationship between quality of life and HIV-related stigma [59-61], this relationship may be mediated by depression [33, 38] and self-efficacy [58]. The association between HIV stigma and depression has been shown to be moderated by individual affect, social support, socioeconomic status, employment status, rural versus urban residence, and disclosure avoidance [32, 35, 62].

\section{Tuberculosis}

TB-related stigma negatively impacts health outcomes by impeding healthcare seeking behavior, care delivery, and recovery (Table 2). Qualitative and quantitative studies have generally shown that stigma delays healthcare seeking, although a recent quantitative study did not find a strong deterrent effect of TB-related stigma when major drivers of healthcare seeking were included in a model [63]. Additionally, TB-related stigma can temporarily diminish social capital during treatment [64], and damage to family reputation can impact

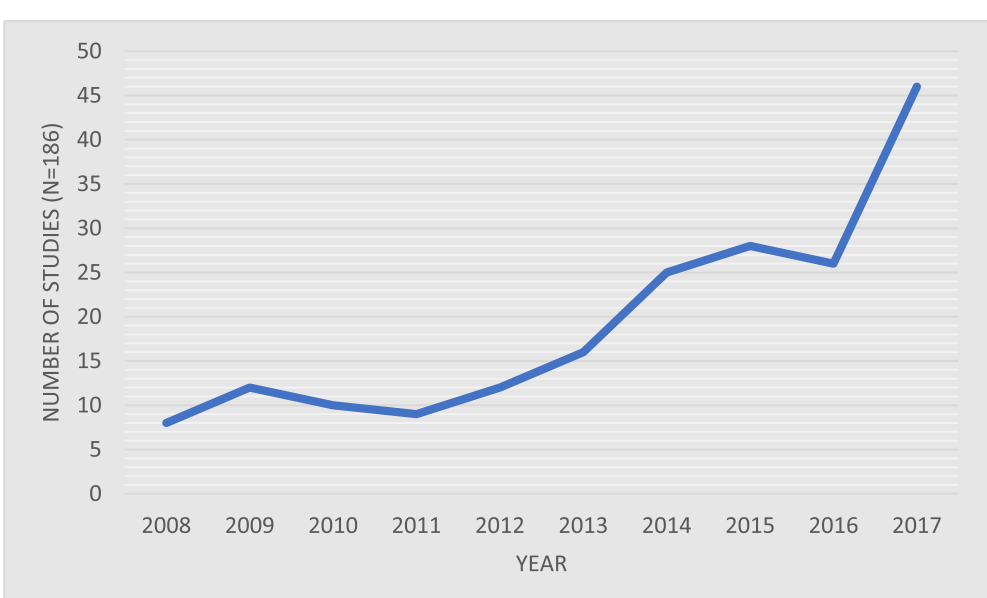

Fig. 2 Number of studies included by date of publication 


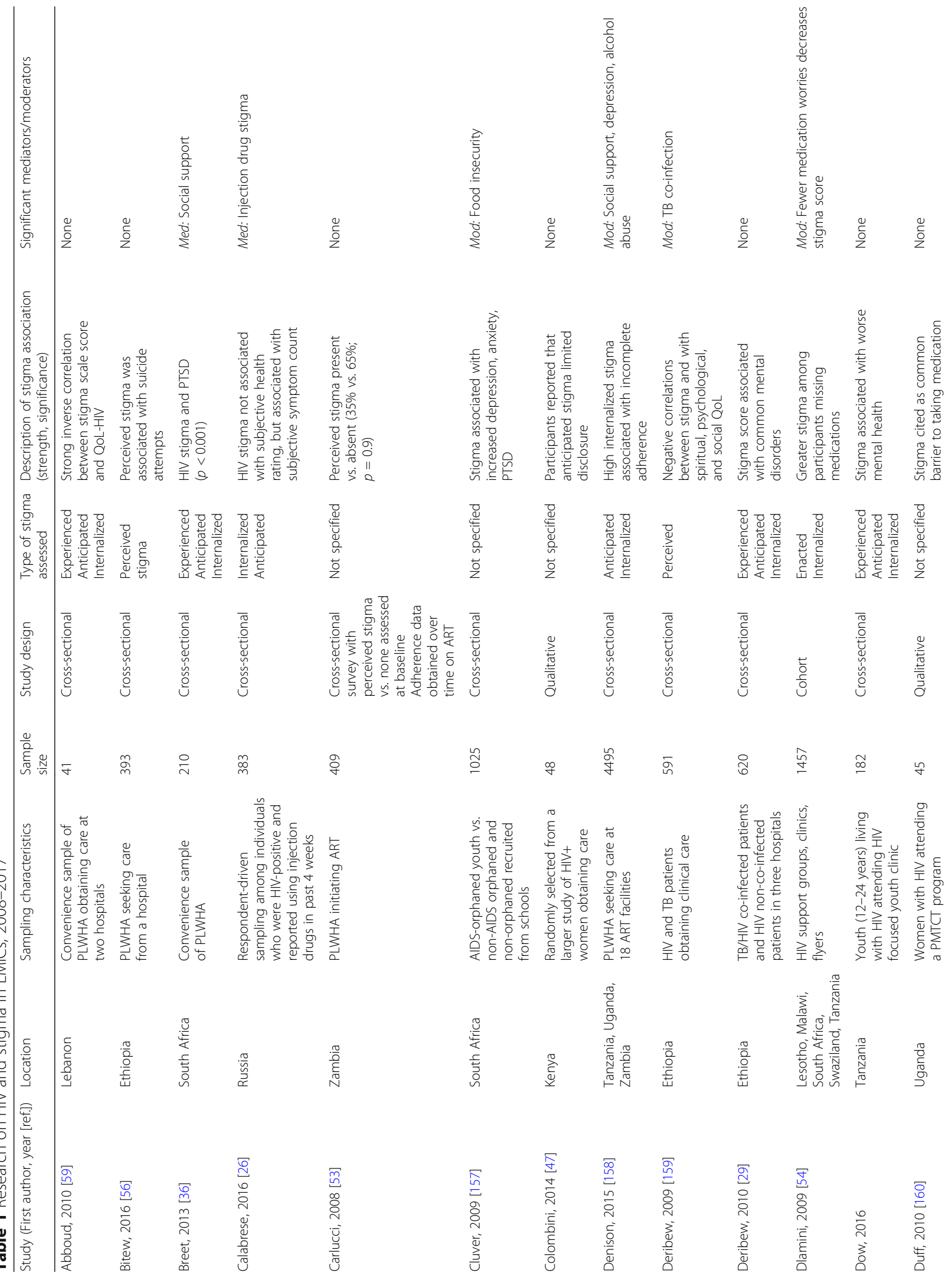




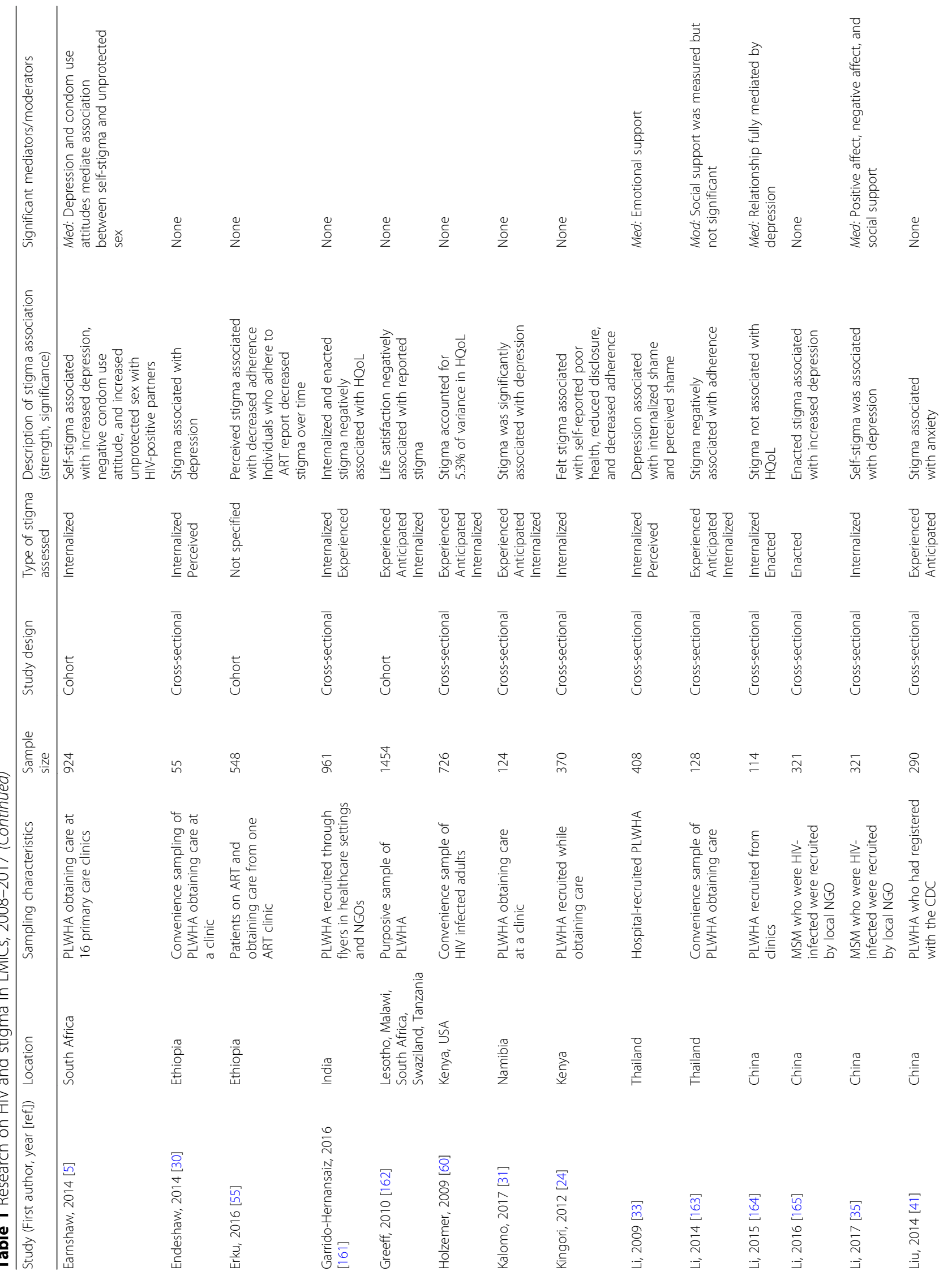




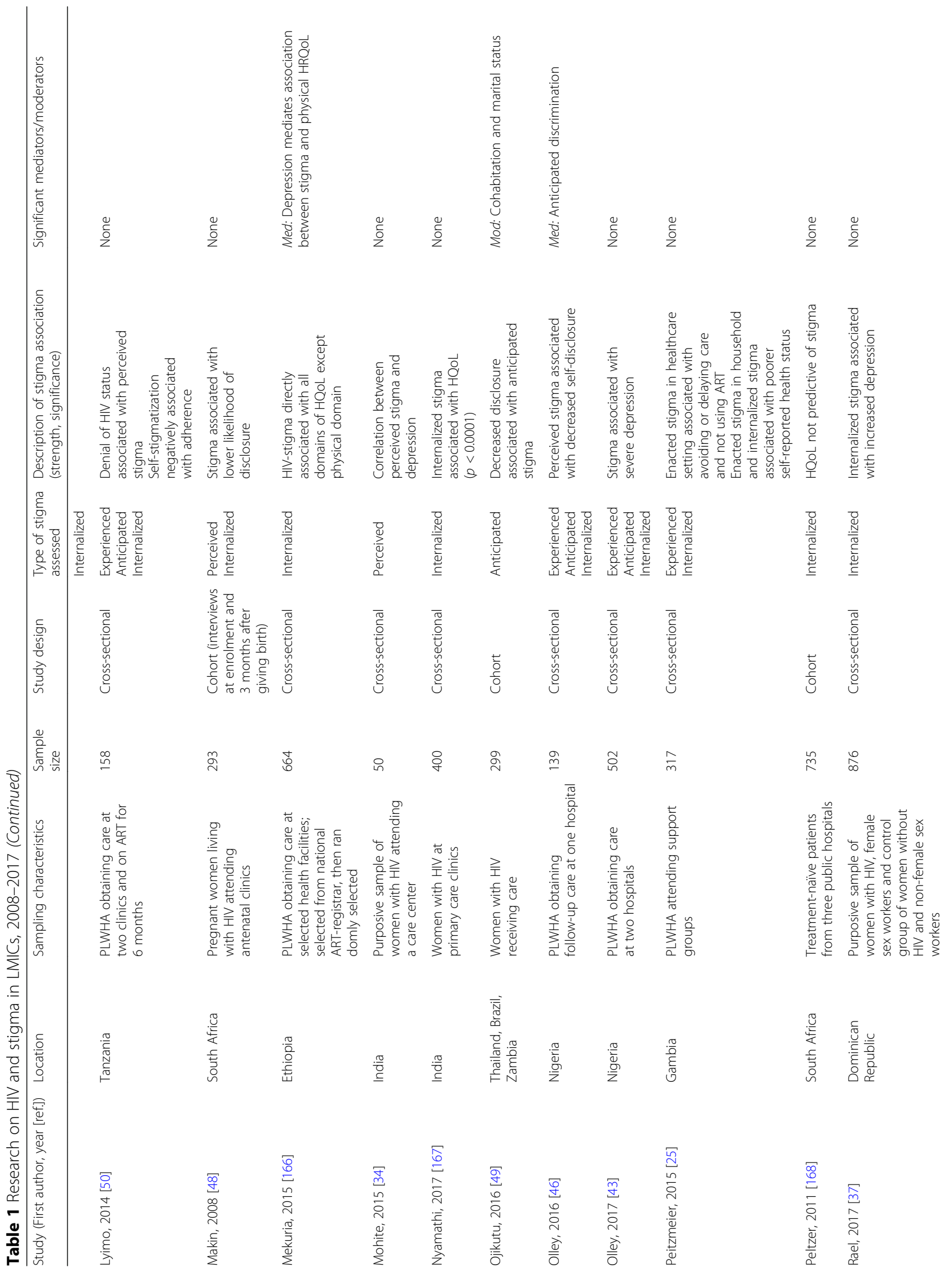




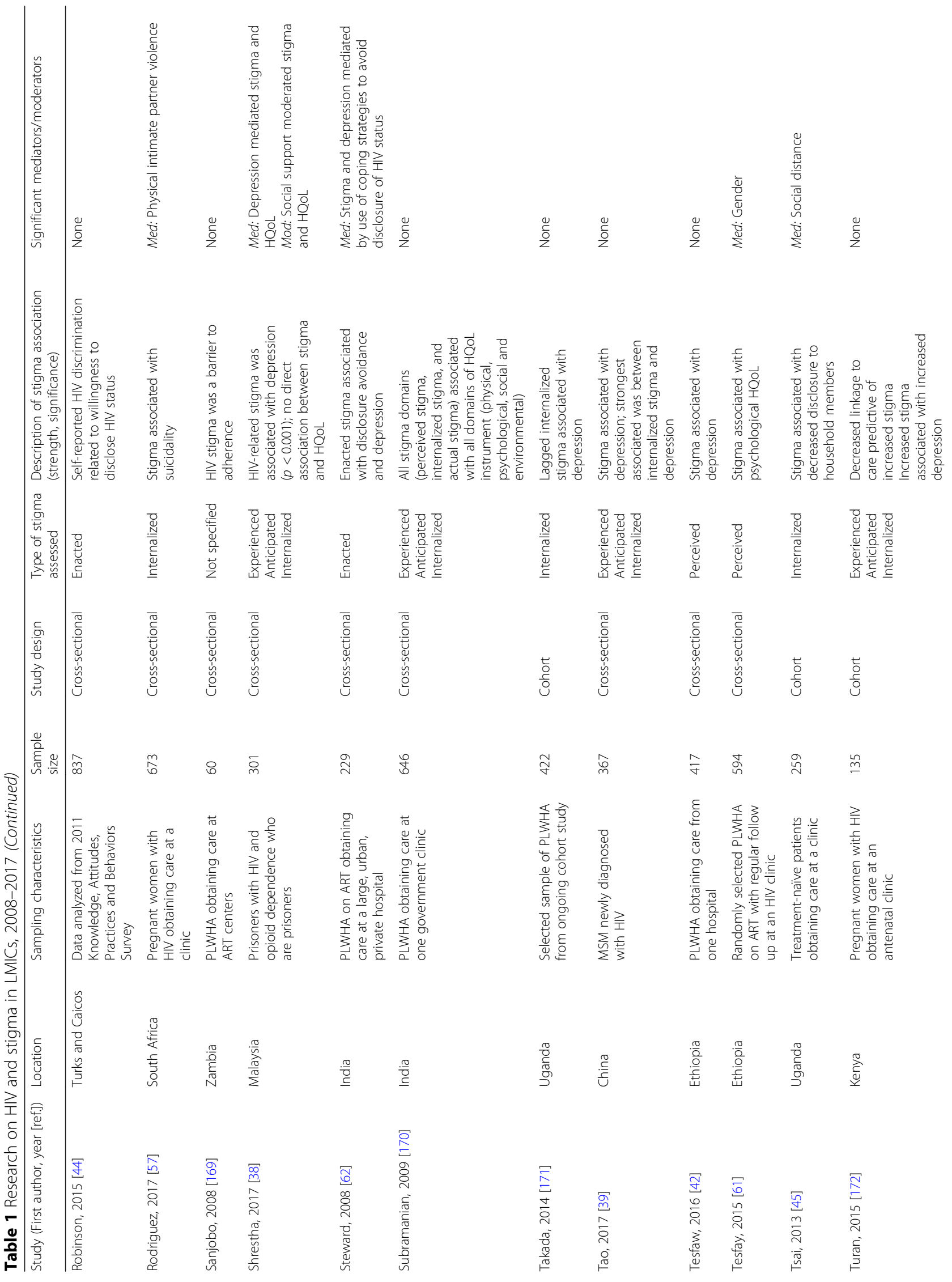




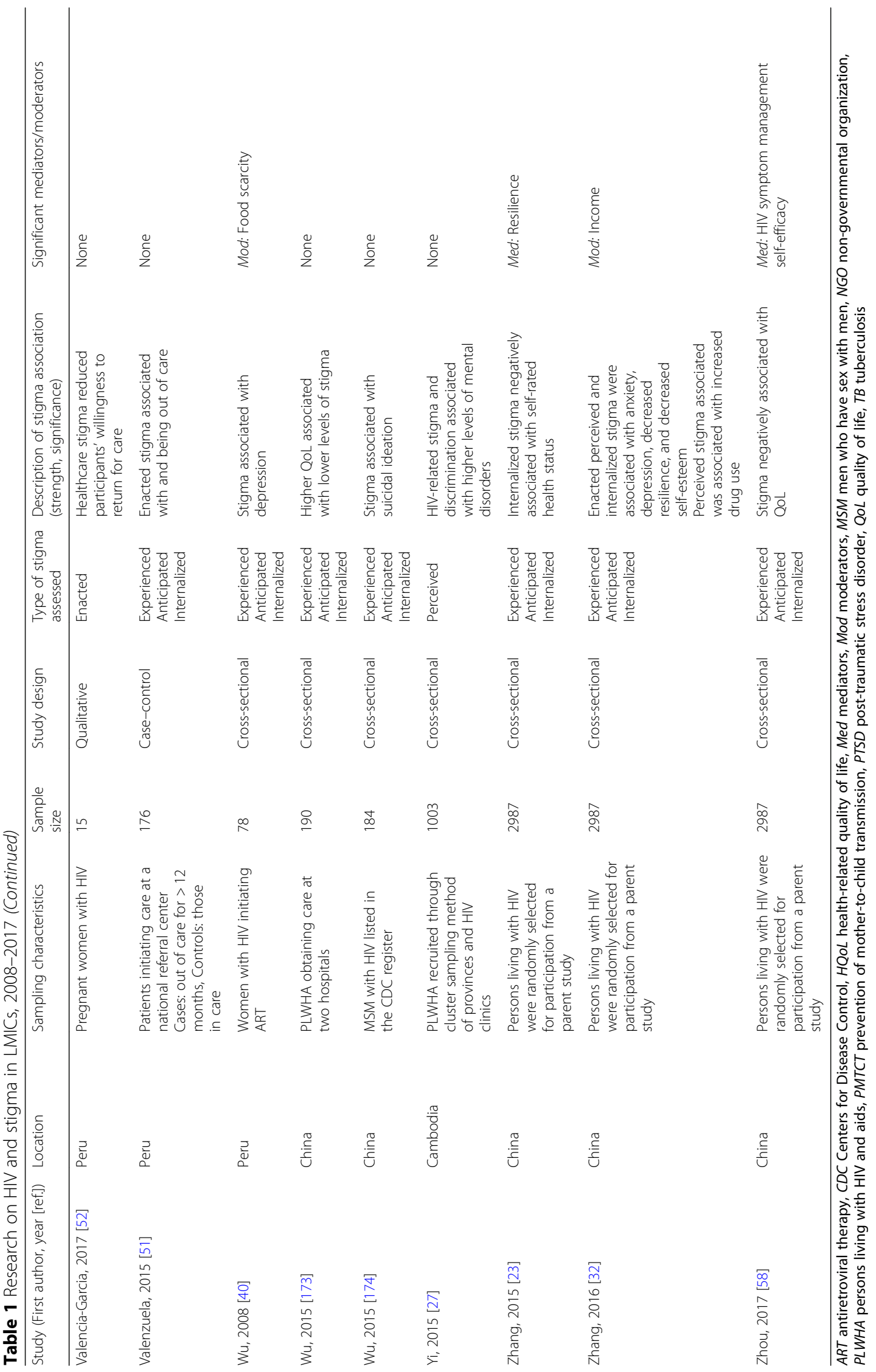




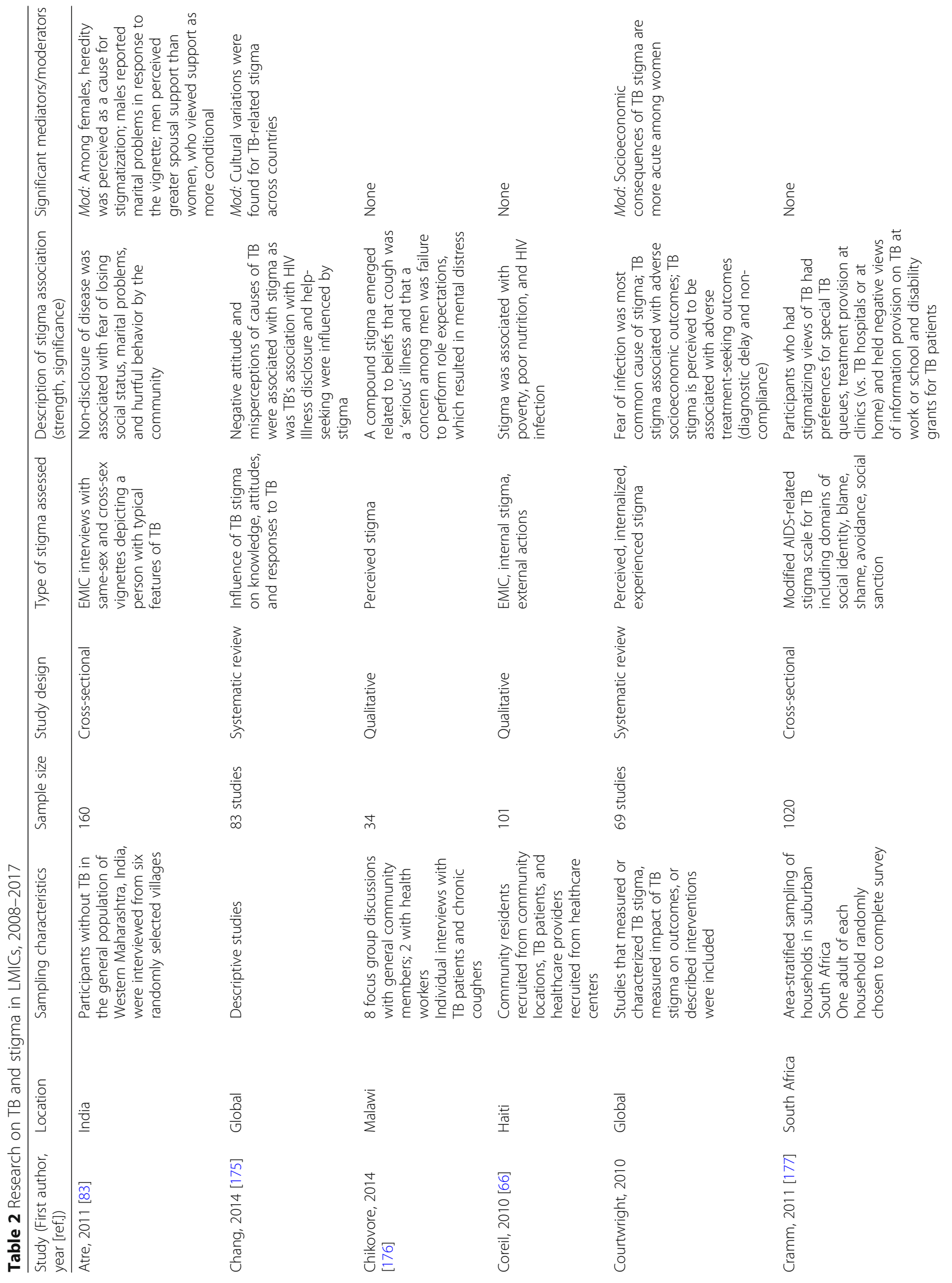




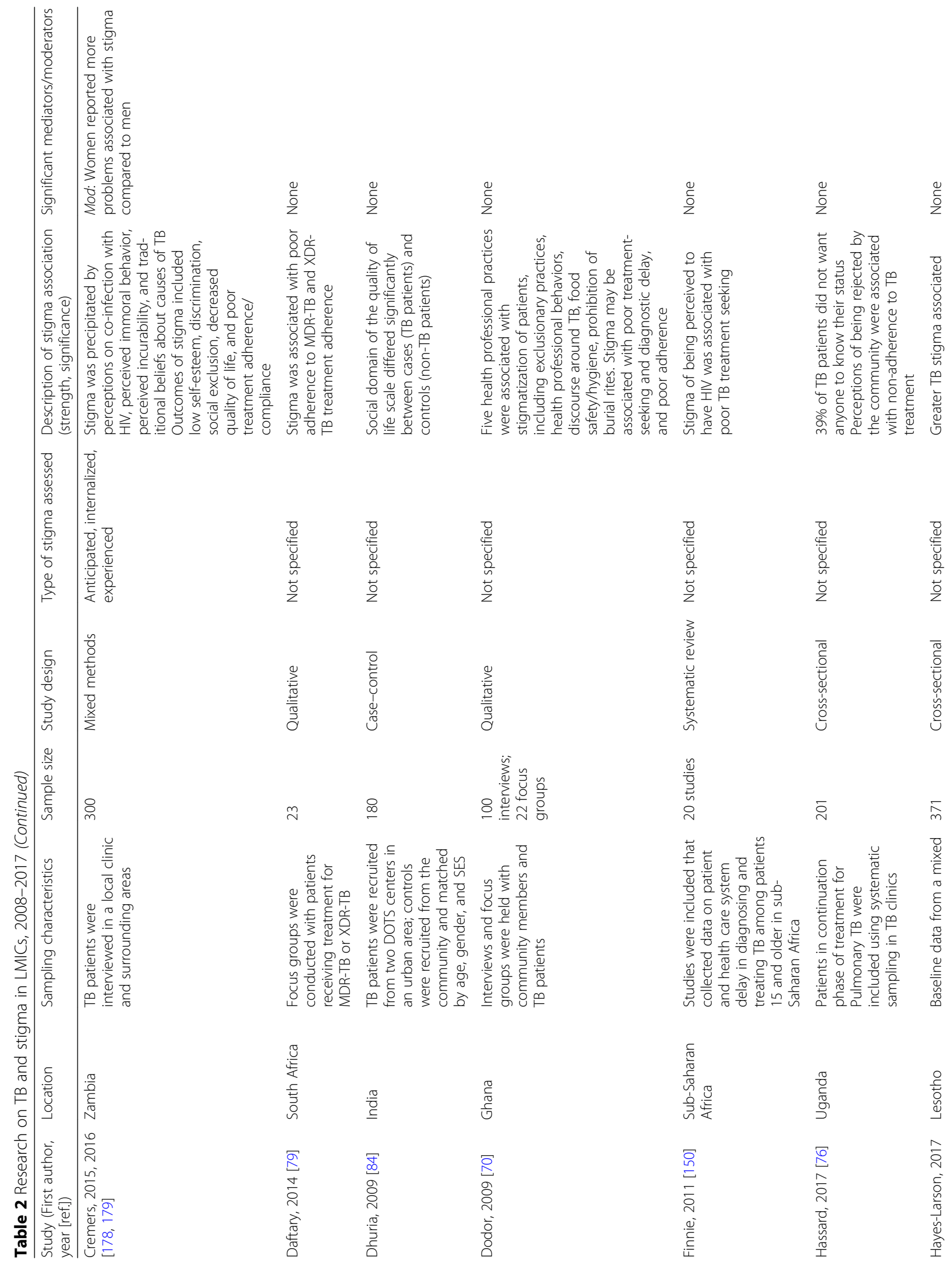




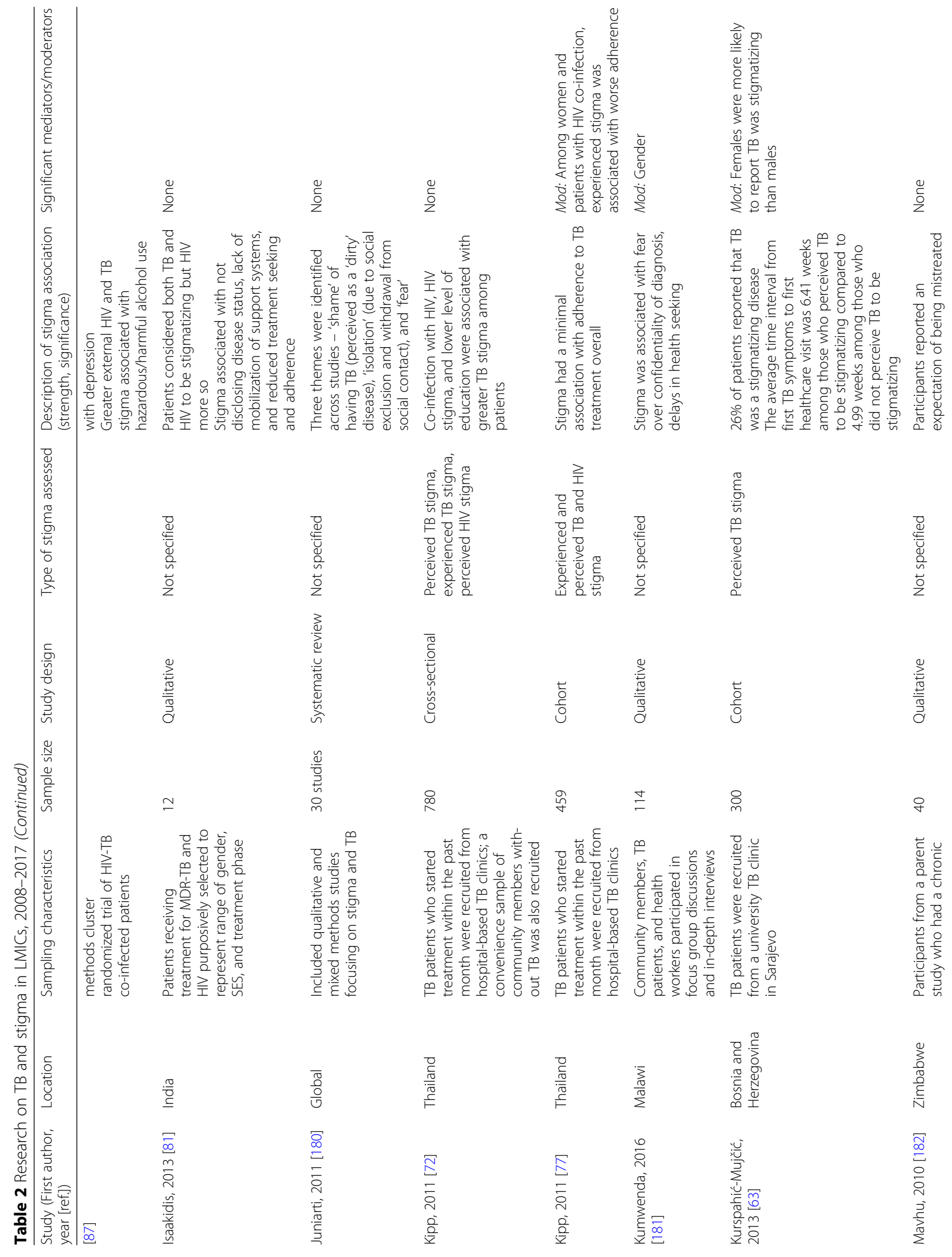




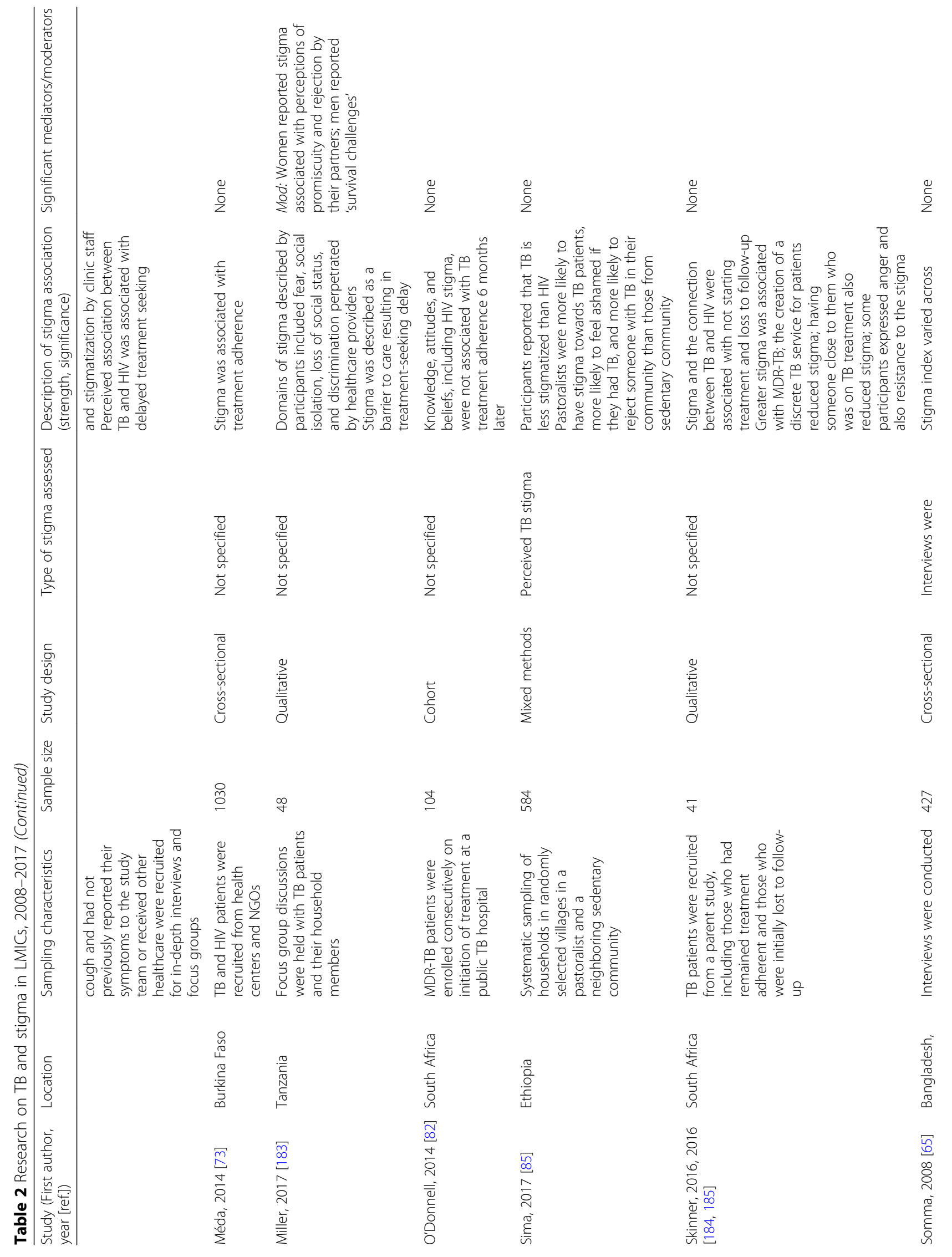




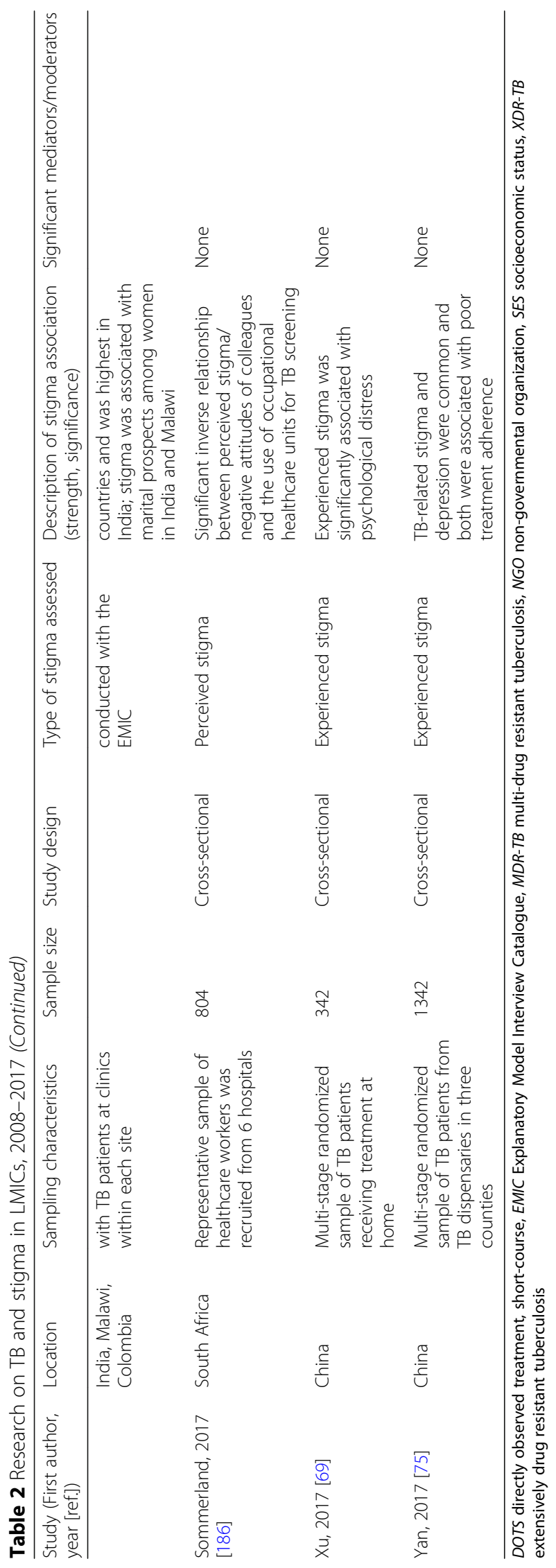




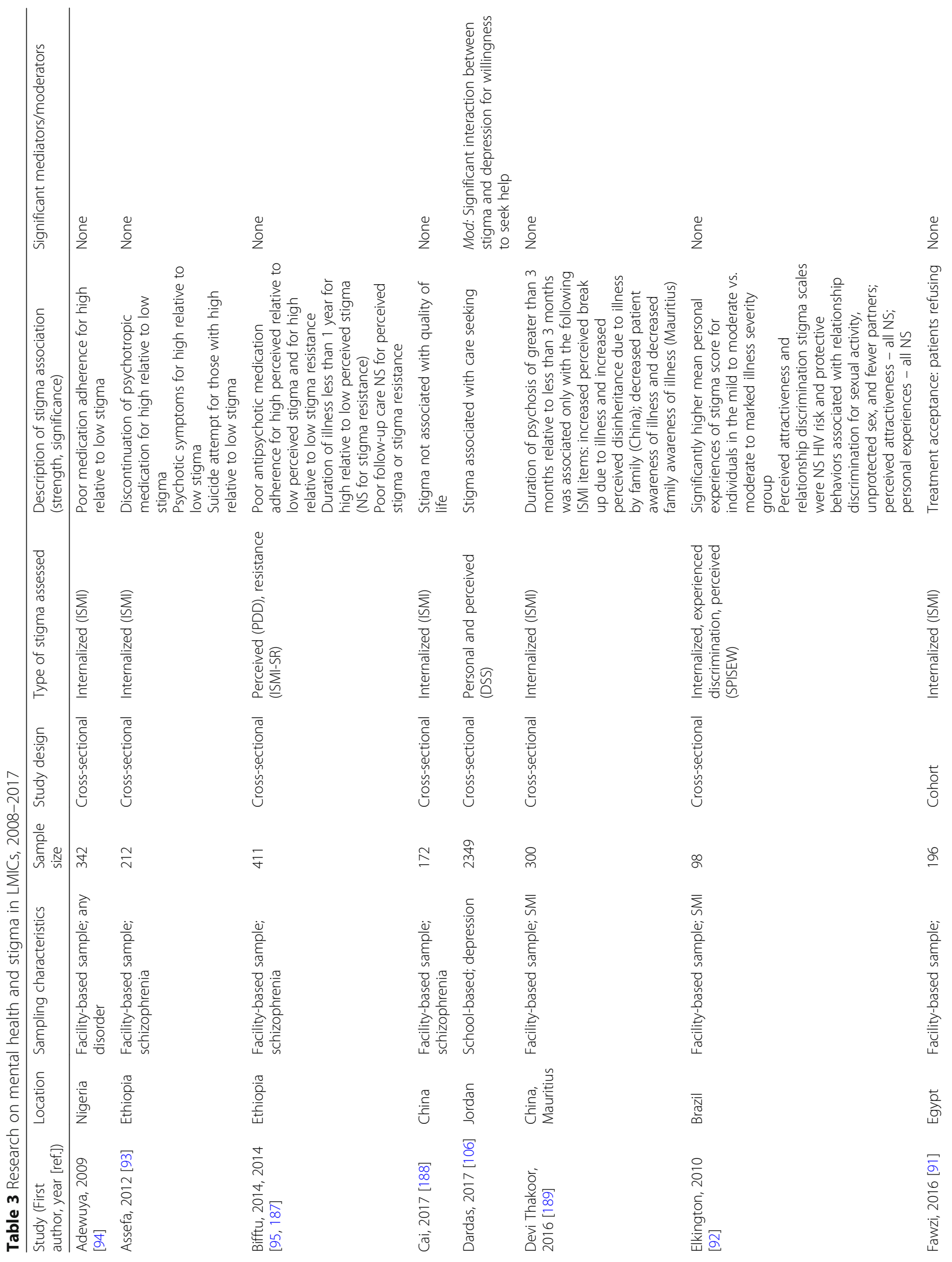




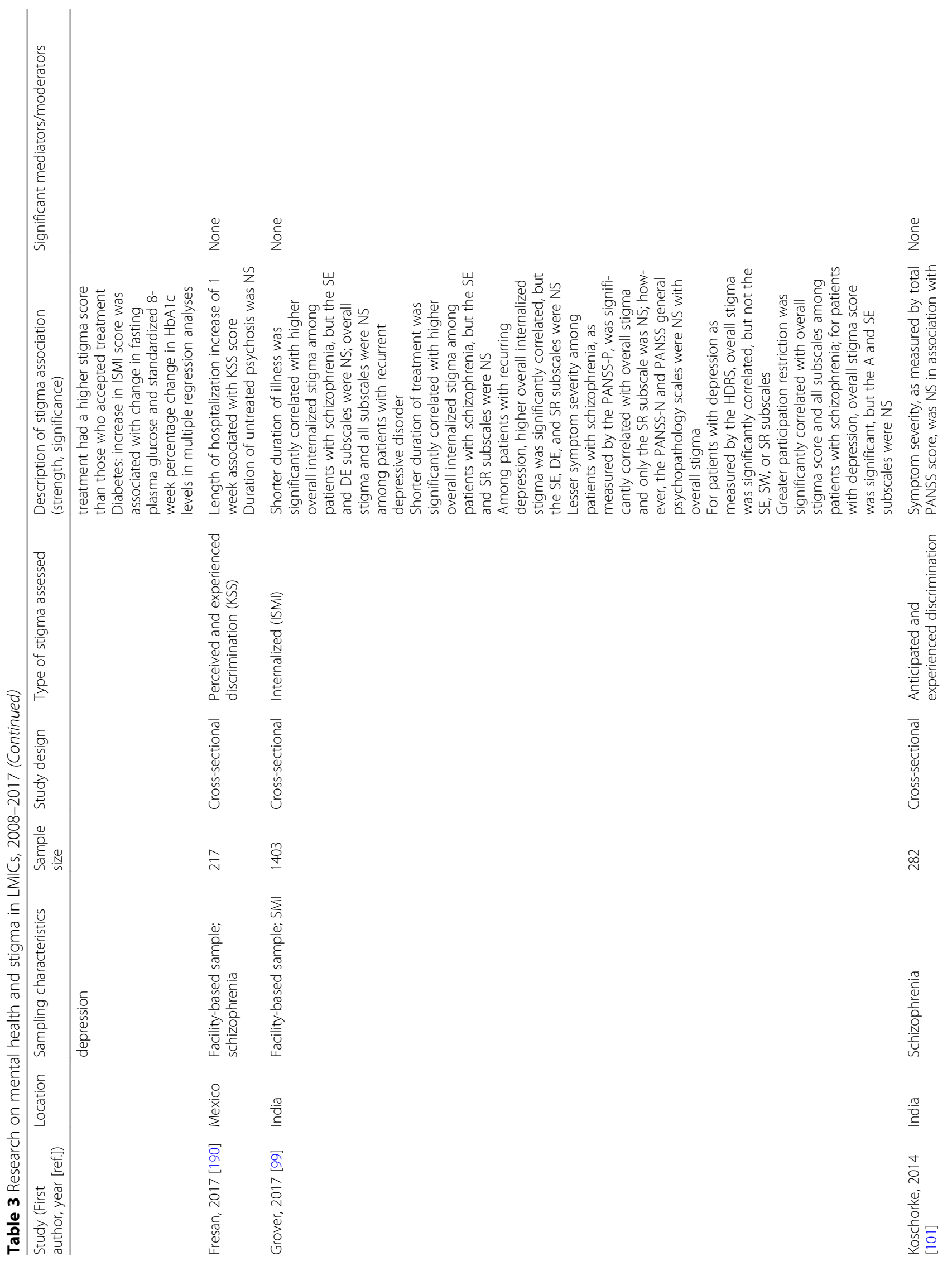




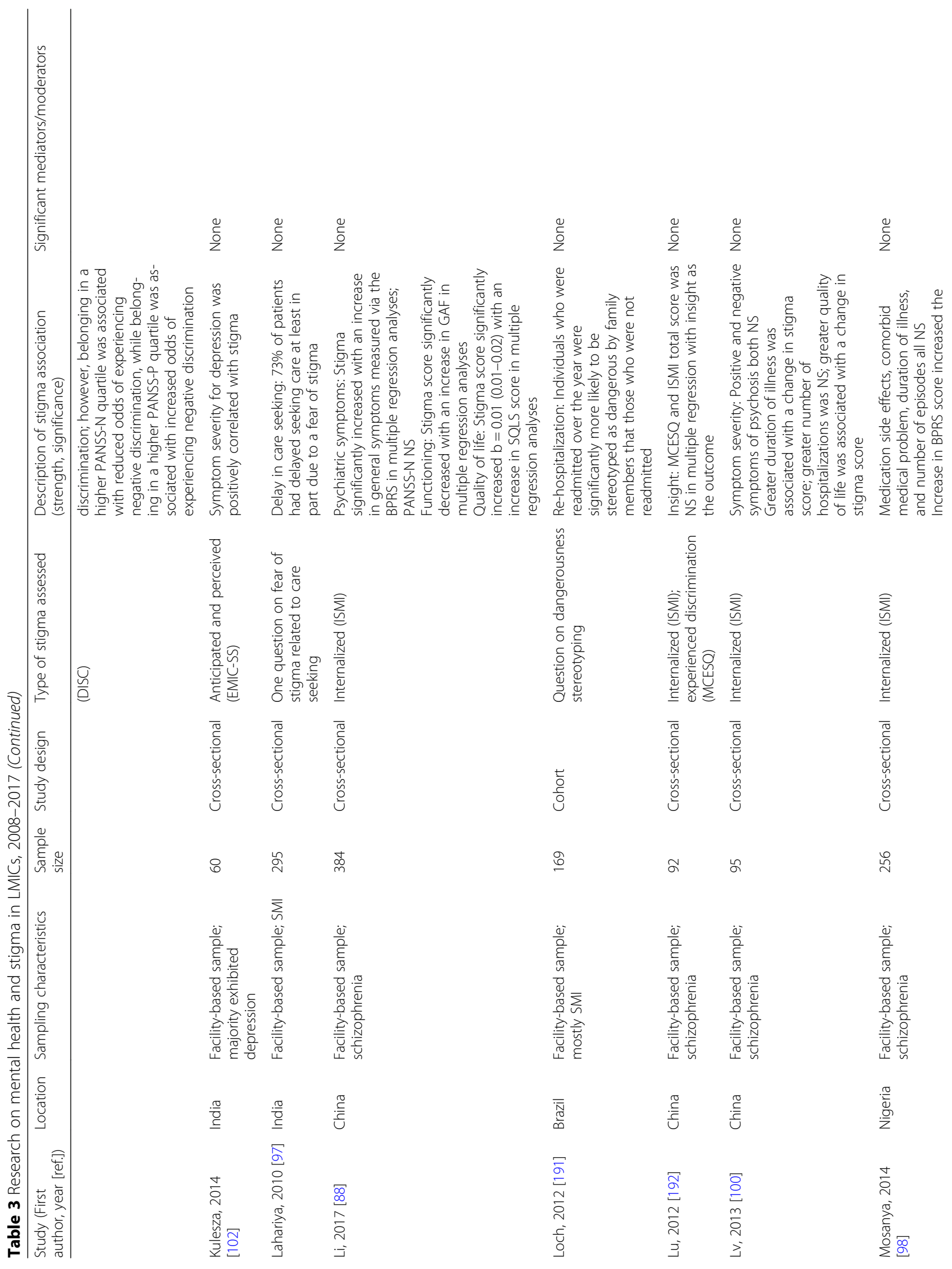




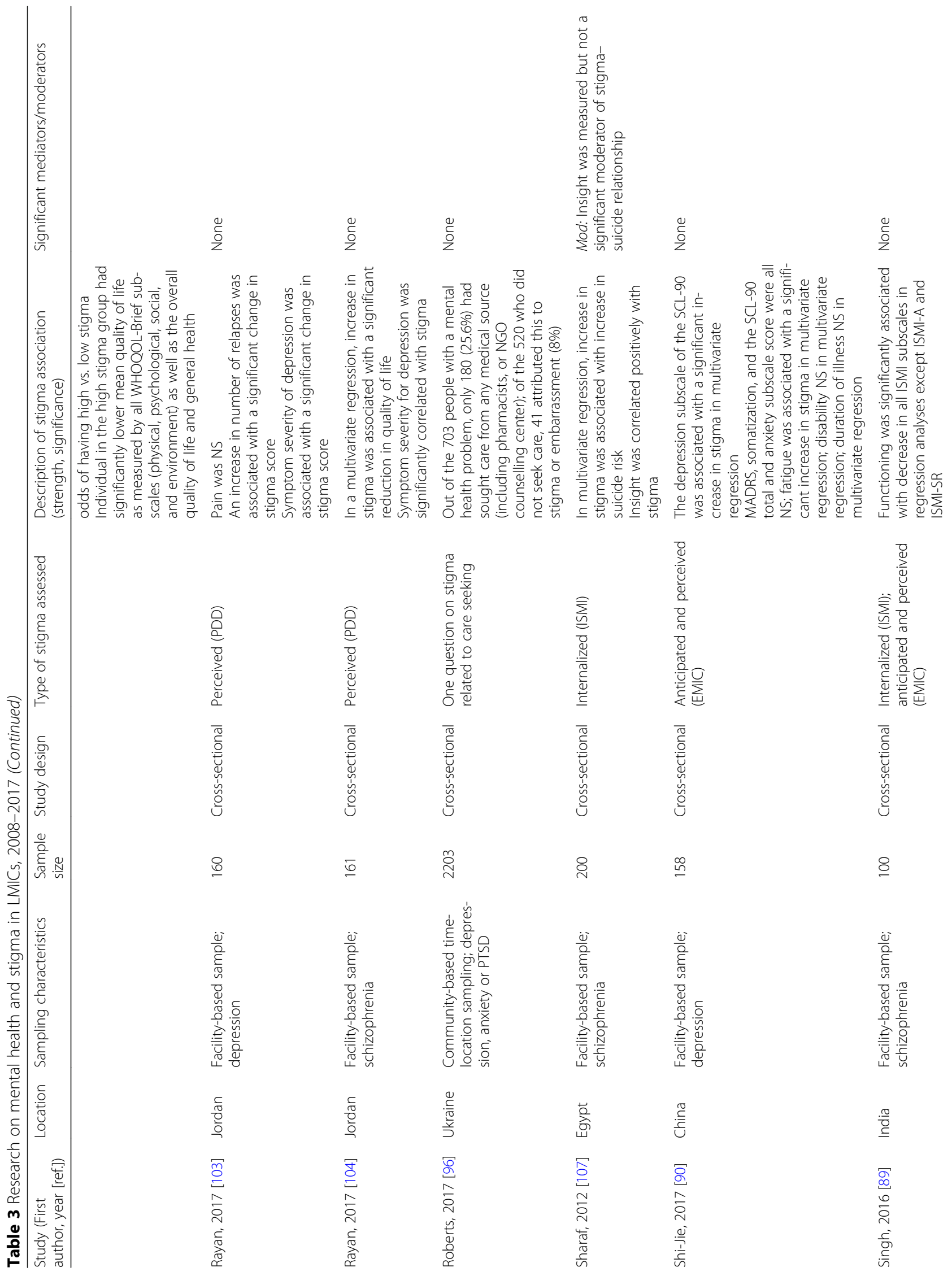




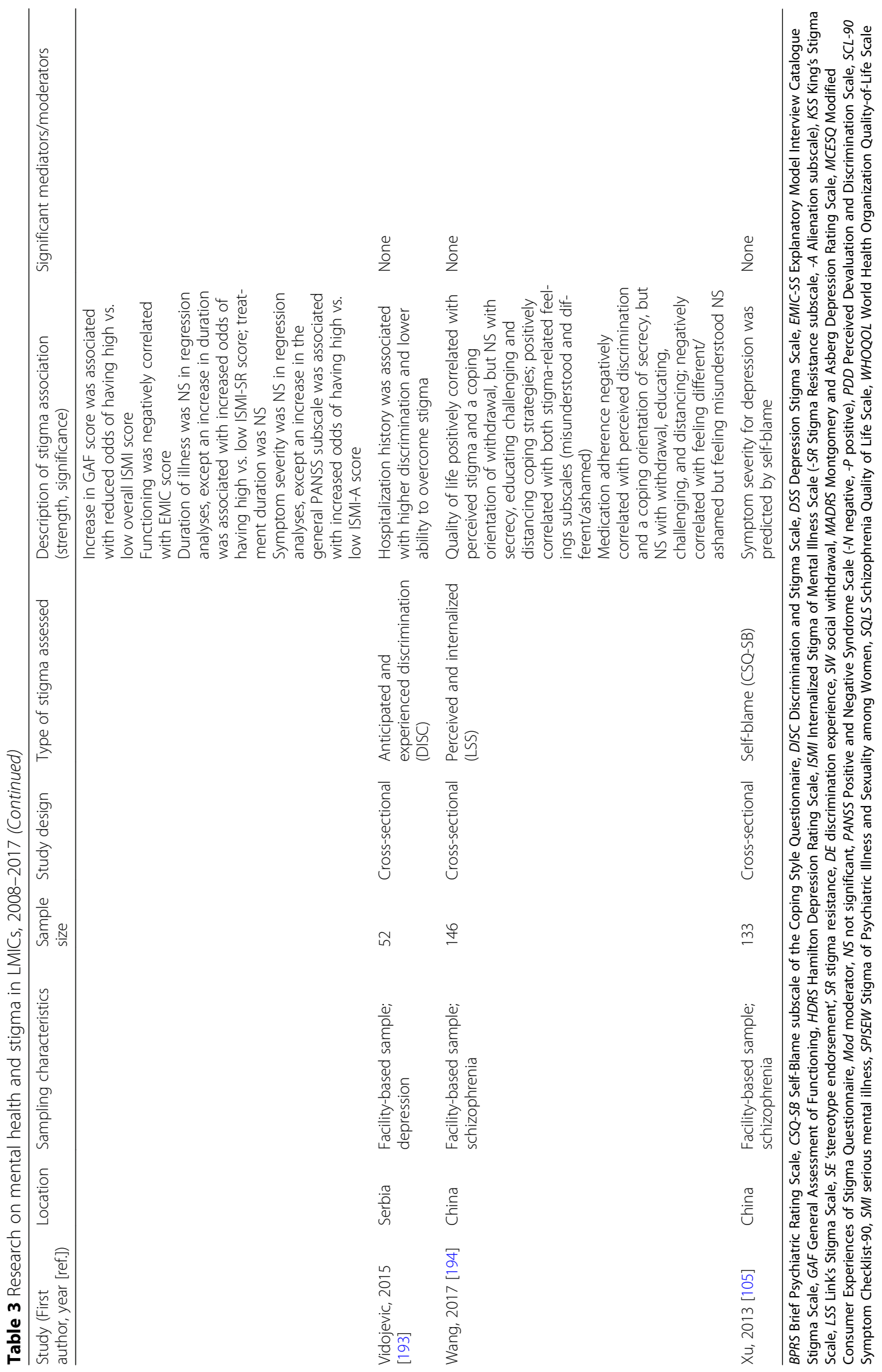




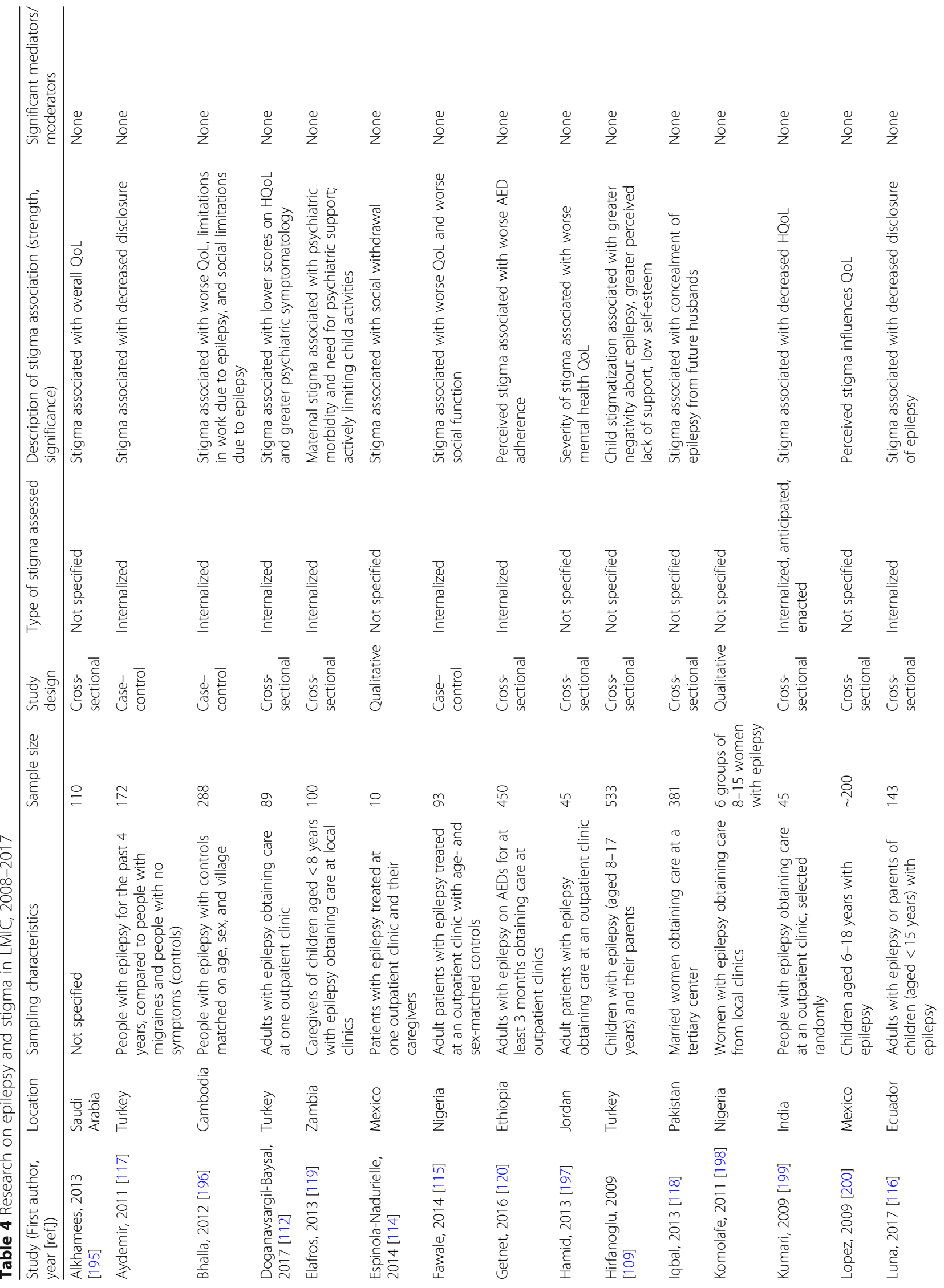




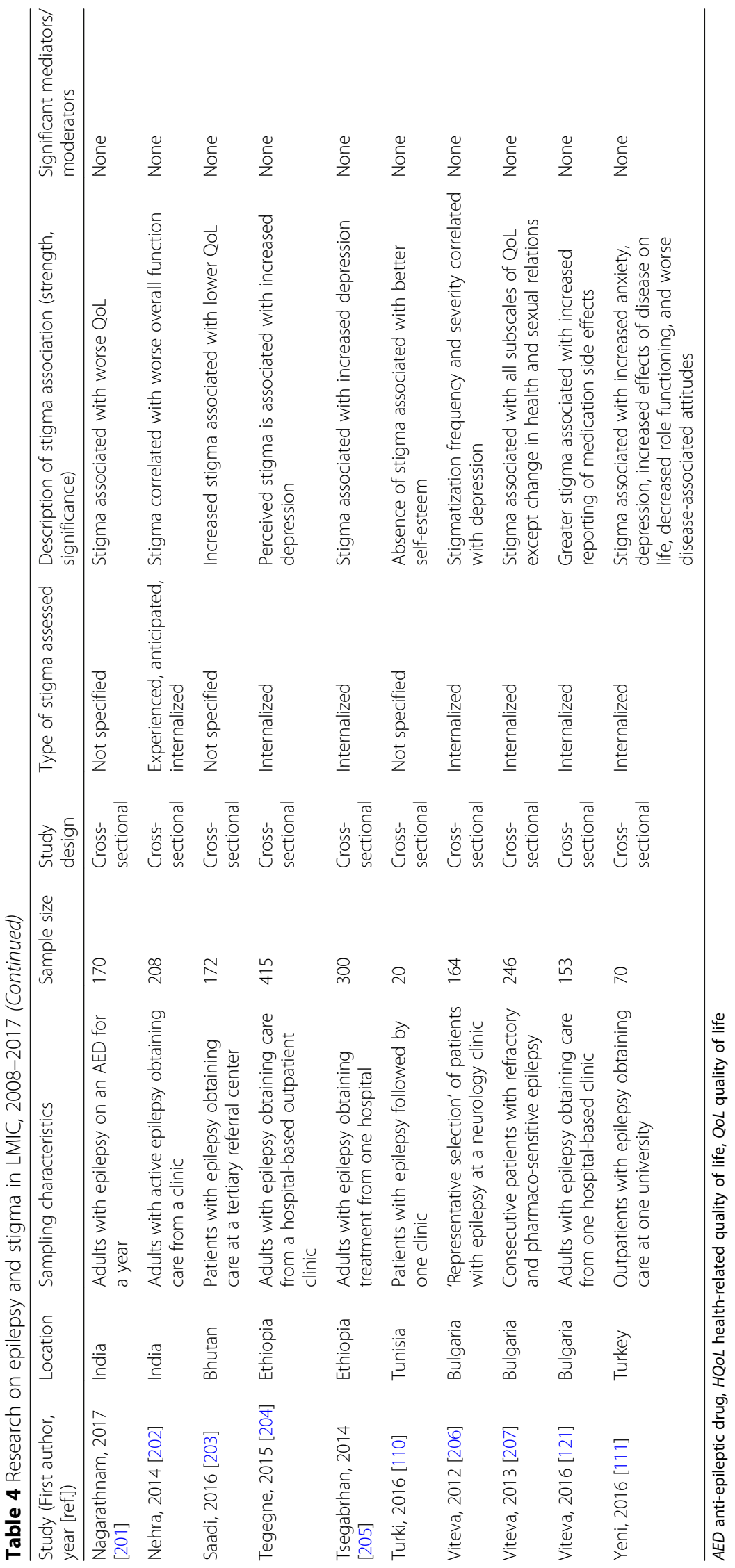




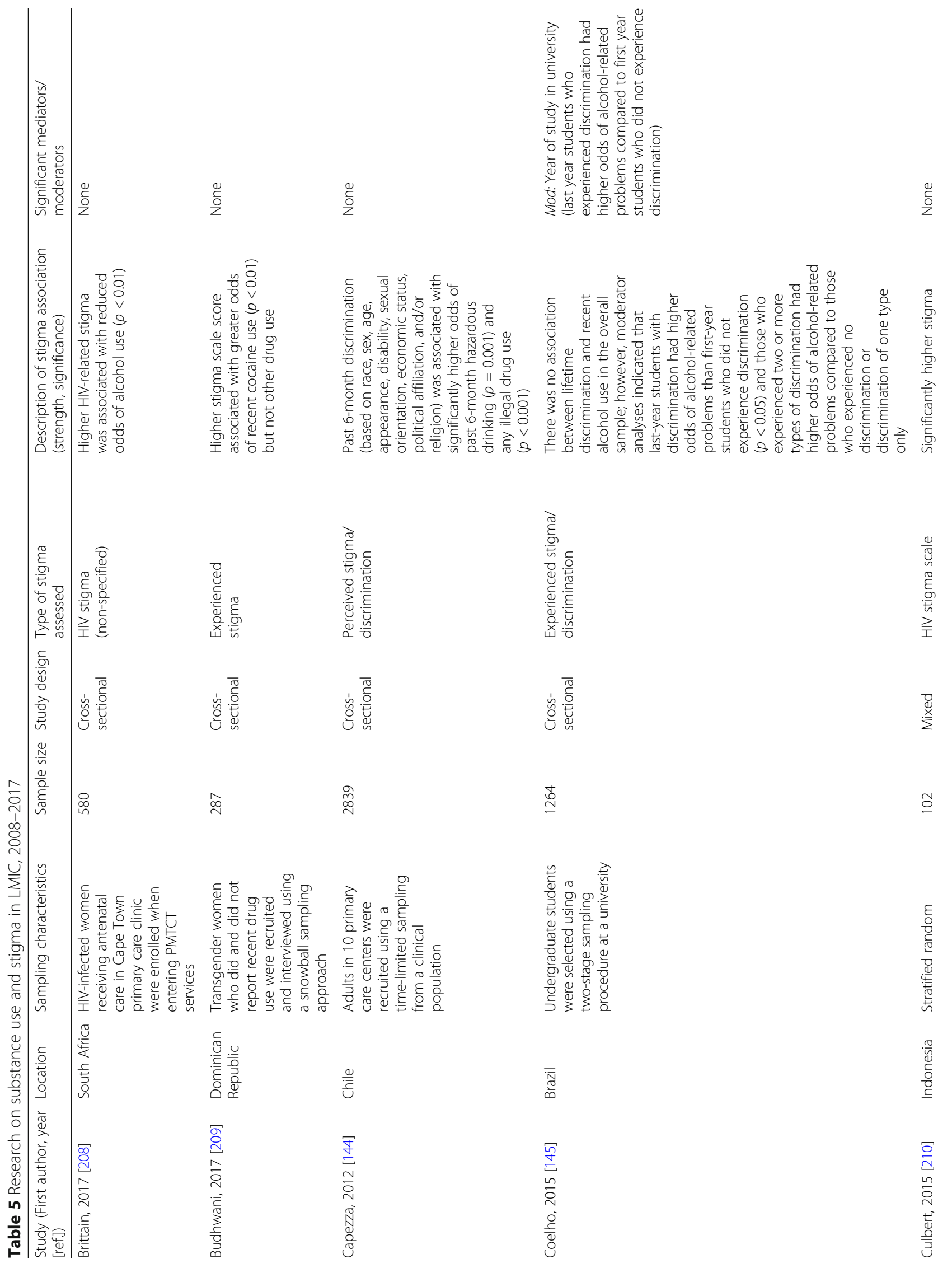




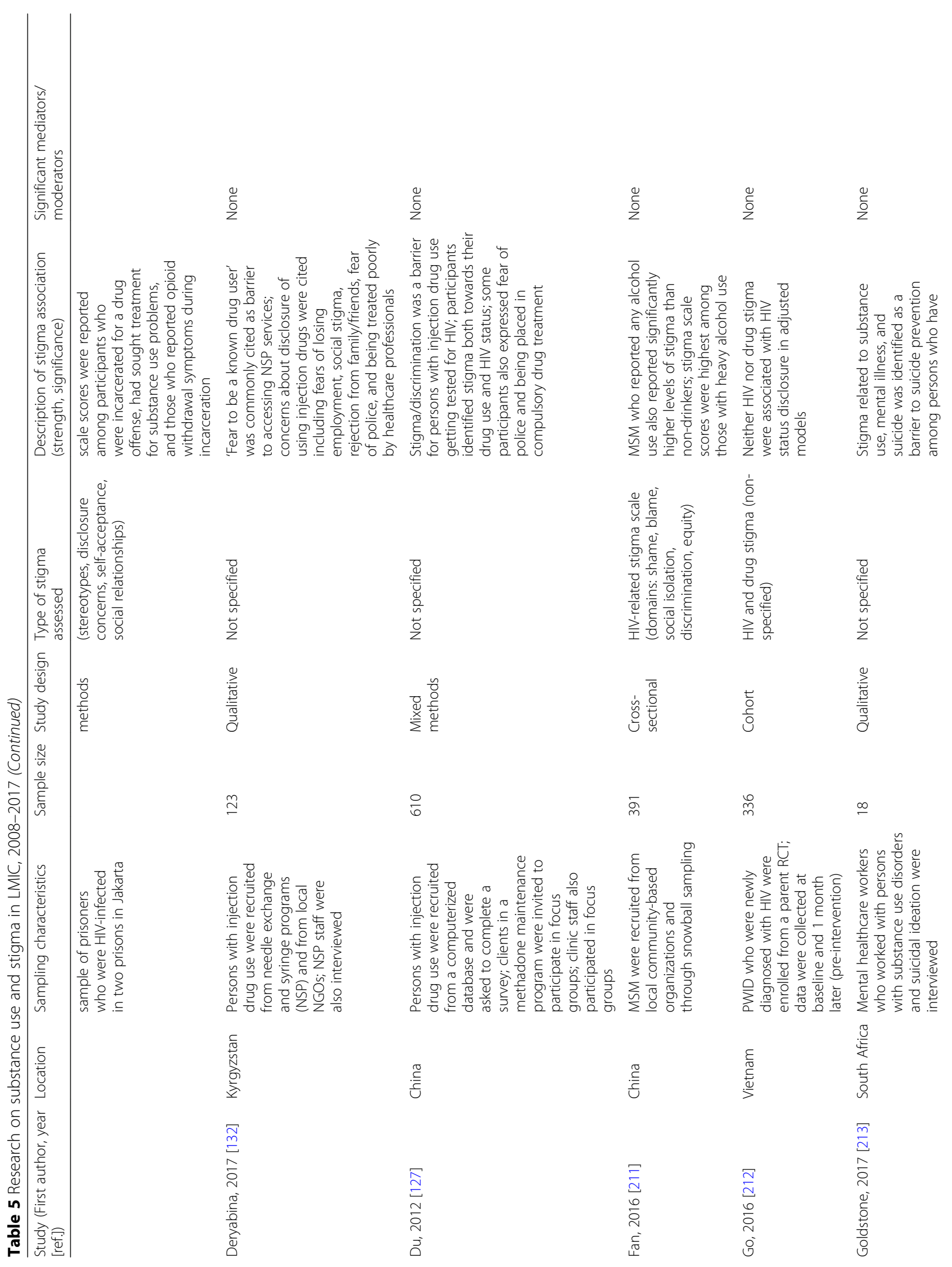




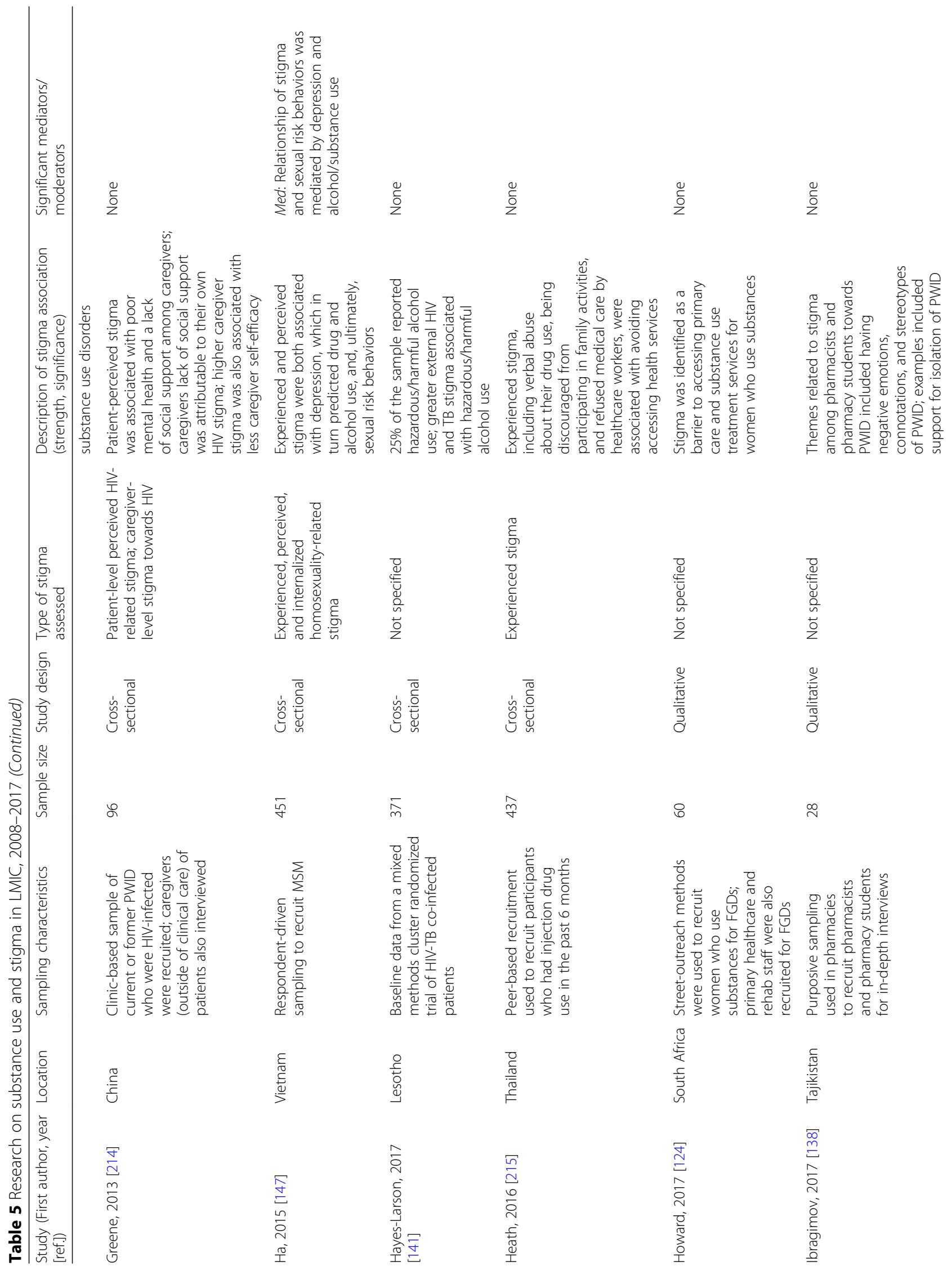




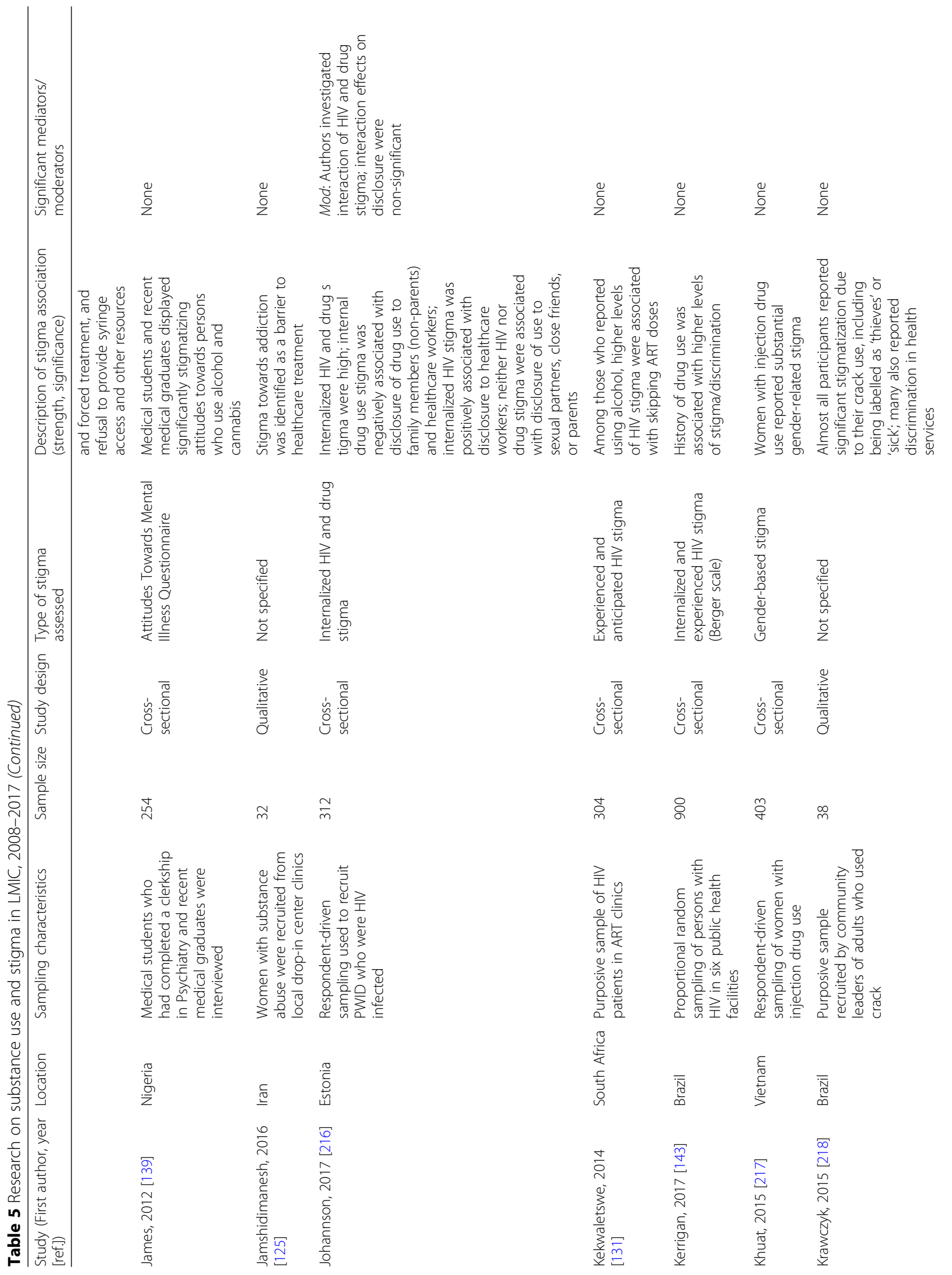




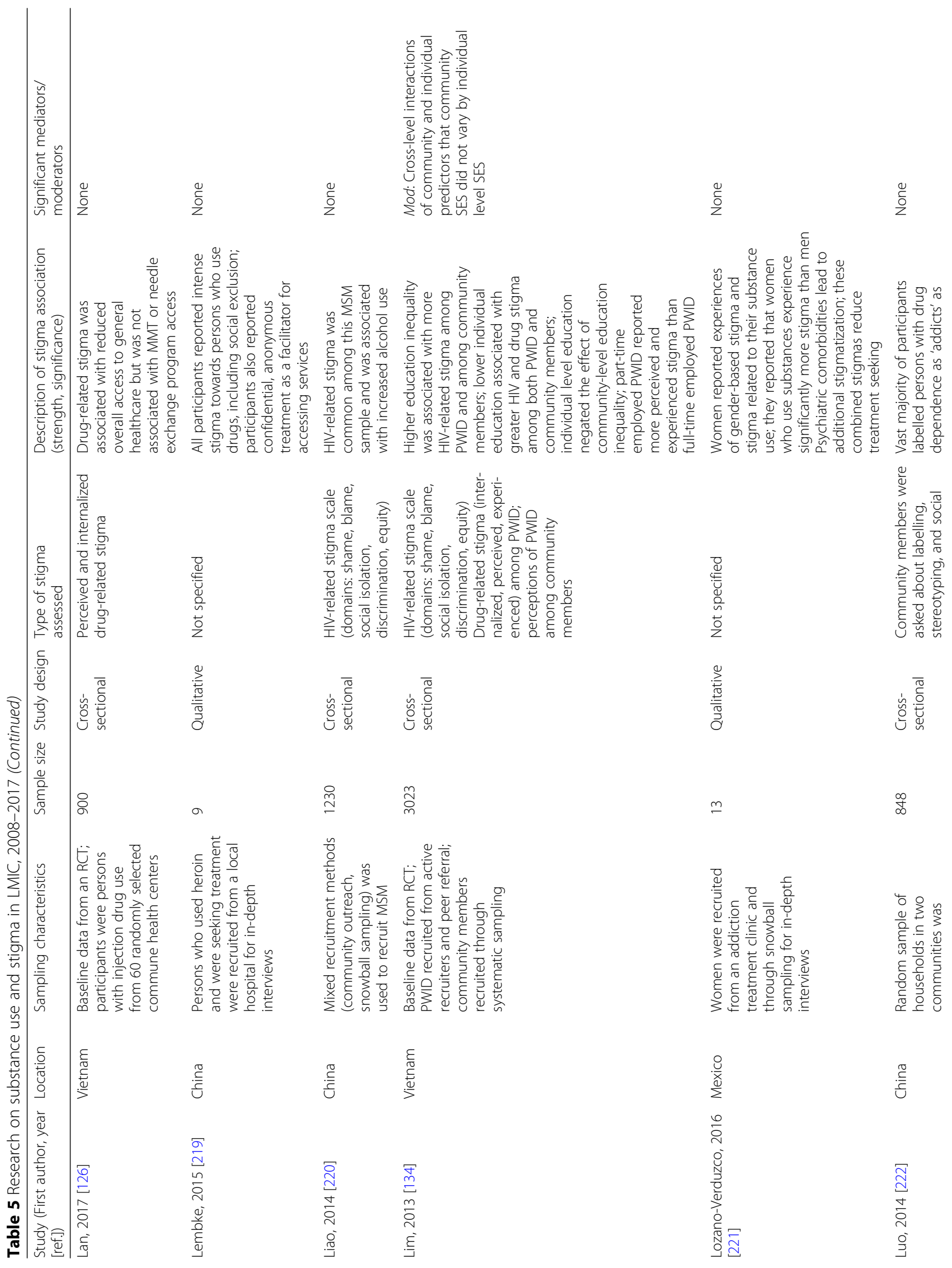




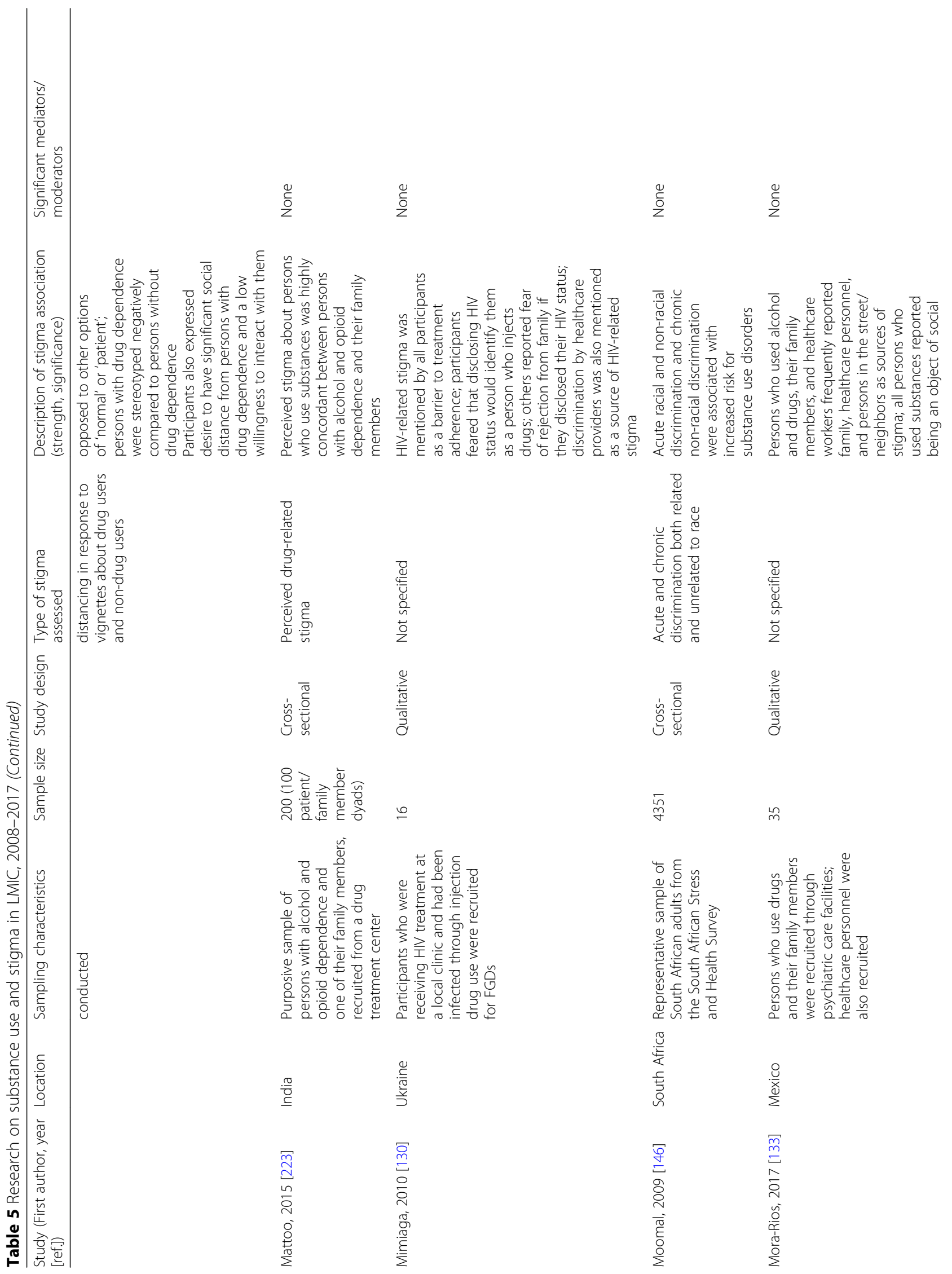




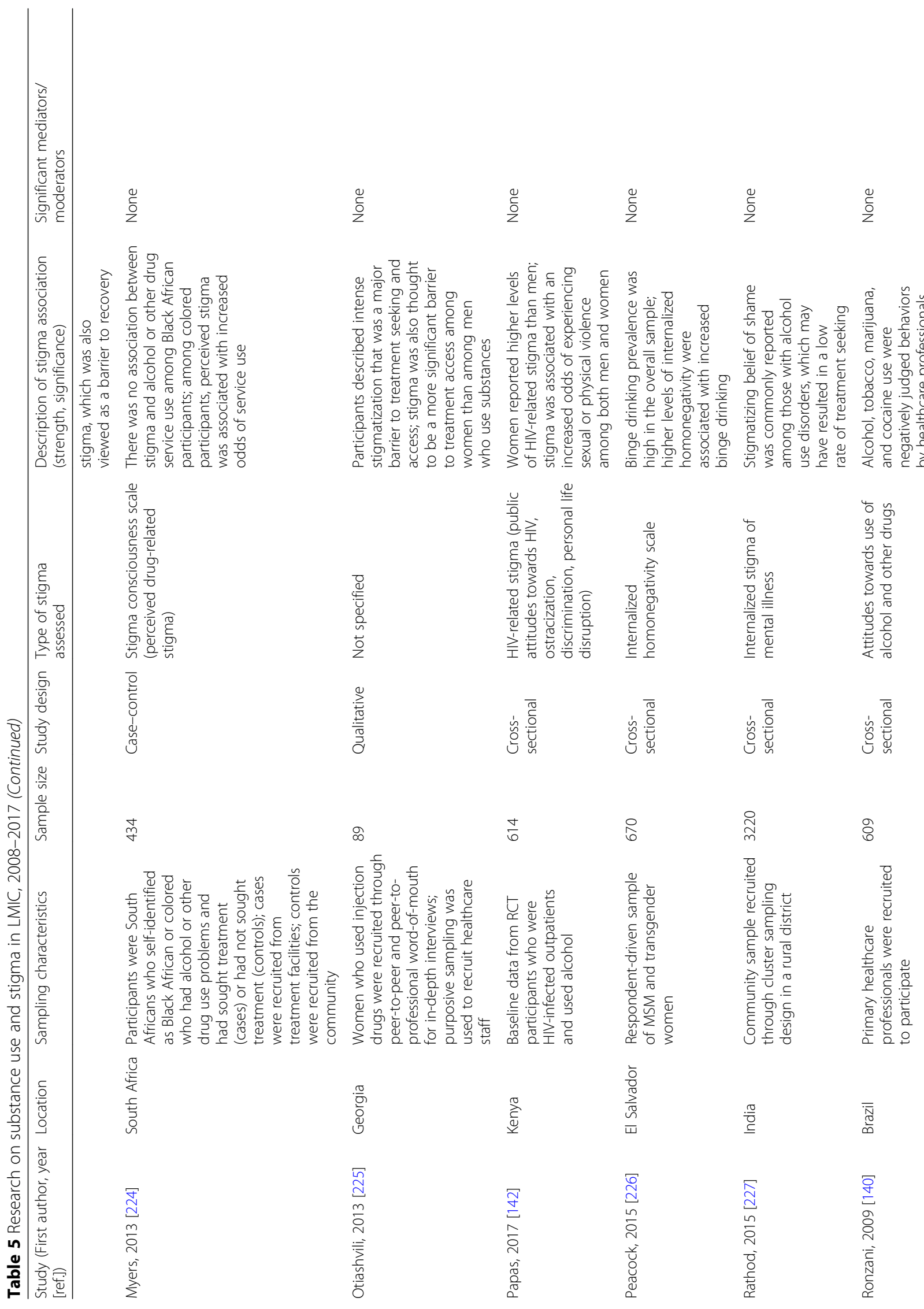




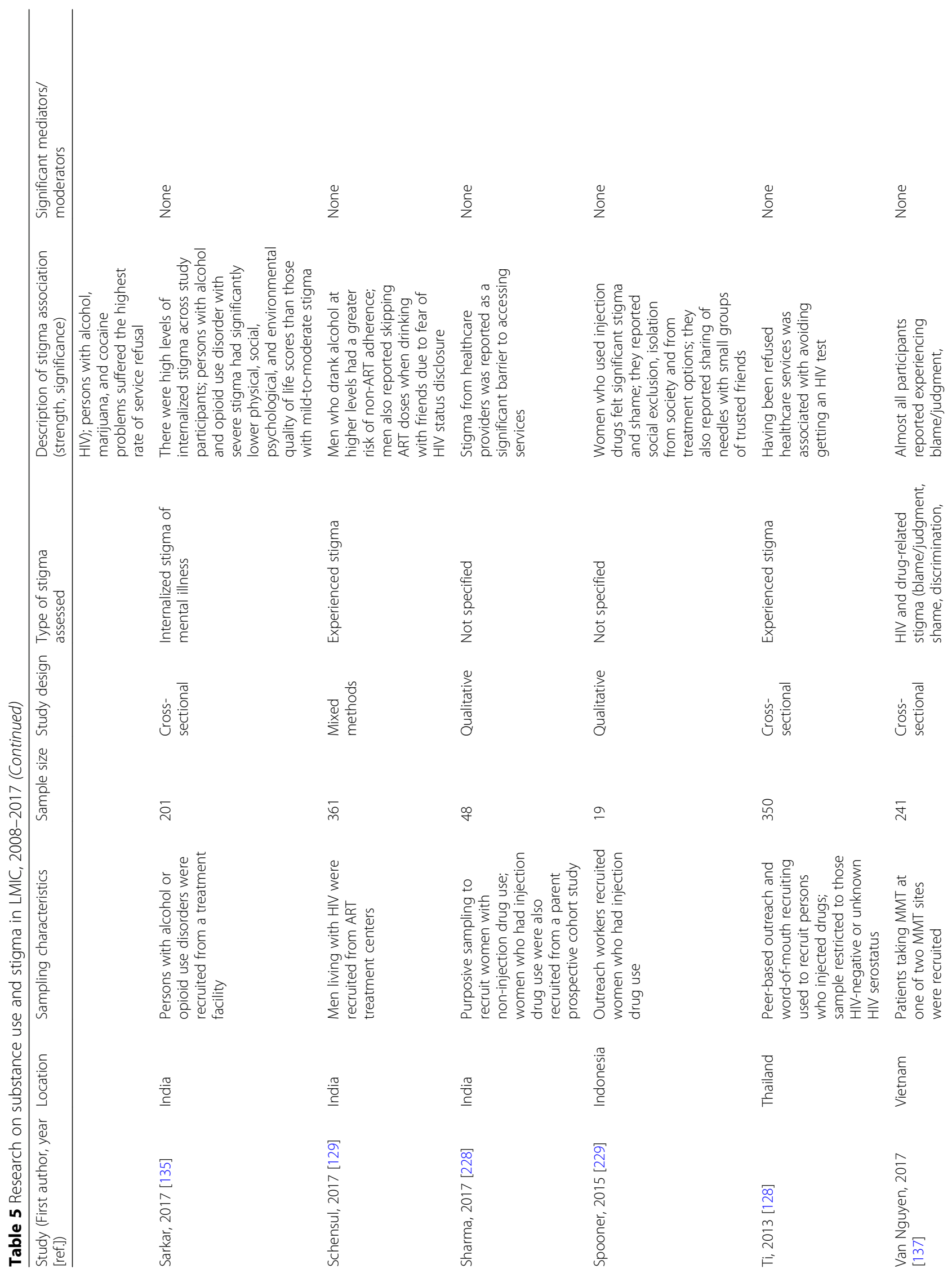




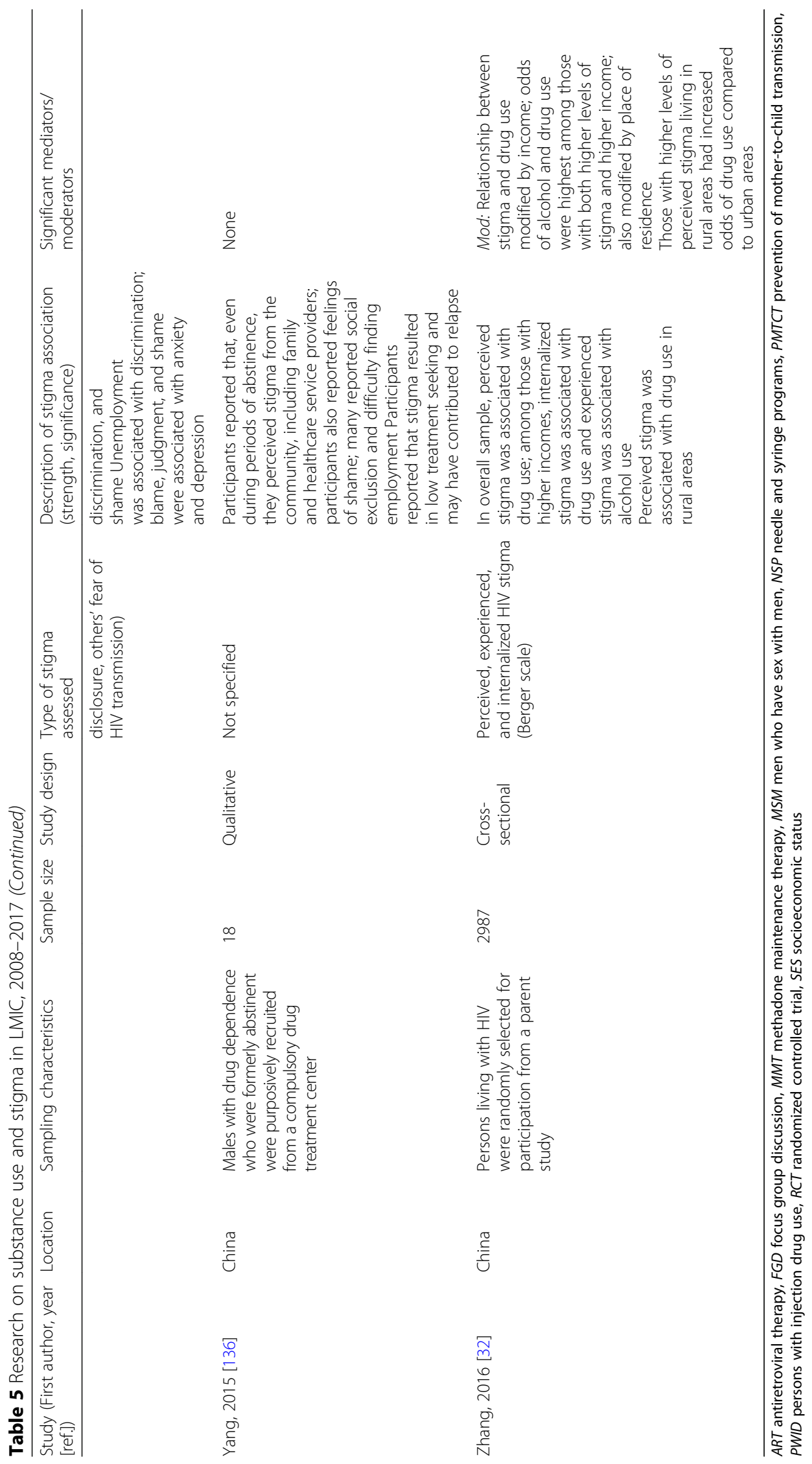


employment, education, and the marriage prospects of its members $[65,66]$.

Secondary stigma may manifest as a reluctance to expedite emergency care for acutely ill family members due to fear of disease disclosure to the broader community [66]. In communities where social capital functions as the safety net, loss of social status can imperil family survival $[66,67]$. TB-related stigma was shown to damage the support networks and quality of services given to those who have a stigmatized condition [66]. Mistreatment of TB patients can contribute to mental health sequelae, poor coping behaviors, and other comorbidities $[68,69]$. TB-related stigma may also erode patients' resilience to disease and household-level wellbeing [70]. Finally, healthcare workers who perceive TB stigma defer TB screening and prophylaxis [71].

Studies have suggested that the impact of stigma on TB treatment adherence varies [72-74], with some suggesting a decrease $[75]$ and others an increase $[76,77]$ in adherence. The predominance of cross-sectional data limits the ability to tease apart this relationship. Much of this variance can also likely be attributable to the diversity across studies with regards to measurement metrics and statistical power [78].

It is likely that drug-resistant TB (DRTB) has a different impact on the association of TB-related stigma with outcomes compared to drug-susceptible TB [79, 80]. DRTB disease may be more susceptible to blame, shame, and self-stigma because healthcare workers often assume it is caused by non-adherence. Further, DRTB treatment side effects can expose DRTB patients to mental health, disability, and poverty stigmas [81]. Stigma fed by perceived dangerousness and isolation policies that erode social capital and resilience may disproportionately affect people with DRTB. DRTB-related stigma may also be considered more of a barrier to adherence than HIV stigma among co-morbid persons [79, 82].

TB-related stigma can be exacerbated or attenuated by other forms of prejudice, including misogyny [83, 84]. Studies of TB-related stigma have also drawn attention to the moderating role of gender. Two studies found women were more adherent to TB treatment when they perceived high levels of stigma, while men were less so, particularly if they found TB treatment humiliating $[65,77]$. There is also evident variation in the health impacts of TB-related stigma among sub-populations (e.g., people who inject drugs, alcohol dependent, pastoralists) [85-87].

\section{Mental health}

Studies have indicated that mental health-related stigma is negatively associated with quality of life, functioning, and other positive health outcomes (Table 3). Quality of life was associated with either internalized or perceived stigma [89] and general functioning was inversely associated with internalized and perceived stigma [88, 89]. Greater stigma was also associated with fatigue [90] and poorer diabetes-related outcomes [91] among those with depression, and with HIV-risk behaviors among those with a severe mental illness [92].

Treatment outcomes were a major area of focus within the mental health articles identified. For example, studies on treatment adherence found internalized stigma to be associated with poorer medication adherence both among those with schizophrenia [93] and among those with any diagnosis of a mental disorder [94]. Perceived discrimination was also associated with higher odds of discontinuing medication among individuals diagnosed with schizophrenia [95]. Data on treatment-seeking behaviors for mental health problems were mixed. For example, one study found that individuals identified as having depression yet rejected treatment were more likely to have higher internalized stigma relative to those who accepted treatment [91]. In a community-based study from Ukraine [96], only $8 \%$ of individuals who were identified as having a mental health problem but not having sought help from any medical source cited stigma as a reason. However, nearly $75 \%$ of individuals living with severe mental illness in India reported delaying seeking care in part due to fear of stigma [97].

Symptom severity was the most common health-related outcome tested for associations with stigma; however, findings on the impacts of mental health-related stigma on mental disorder symptom severity are mixed. For example, two studies found that, among those diagnosed with schizophrenia, those with higher levels of internalized stigma had greater general psychiatric symptoms $[88,98]$. In contrast, two studies found no relationship between general symptoms of psychopathology and most forms of internalized stigma assessed $[89,99]$, and one study found fewer experiences of stigma among those with more severe general psychiatric symptoms who were living with a severe mental illness [92]. Findings related to symptoms specific to schizophrenia were similarly mixed. Negative schizophrenia symptoms were not significantly associated with most forms of internalized stigma [35, 89, 99, 100]. Of three studies examining positive symptoms of schizophrenia [99-101], two found significant associations with stigma operating in opposite directions [99, 101]. For individuals with depression, greater symptom severity was associated with greater perceived stigma [90, 102-105], though one study found less stigma among those with higher levels of symptoms [99].

Moderators were assessed in only two studies on mental health-related stigma and health outcomes and no studies assessed mediators. In Jordan [106], depression was a moderator of the relationship between stigma and treatment seeking. Adolescents with mild depression who reported high levels of stigma were more likely to 
seek care from a variety of sources (counselor, general practitioner, religious leader, or family member) and express willingness to take medication or receive therapy than adolescents with mild depression who reported low levels of stigma. While moderate to severe depression was associated with lower likelihood of seeking care overall, there was no association between stigma and care-seeking for adolescents with moderate to severe depression. In Egypt [107], insight did not significantly modify the relationship between stigma and suicide risk among persons with schizophrenia.

\section{Epilepsy}

Epilepsy-related stigma has been repeatedly linked to poor quality of life and associated with increased epilepsy-related concerns [108, 109], poor self-esteem [110], and increased self-reported burden of disease [111], including increased psychiatric burden such as that attributed to anxiety and depression [111-113] (Table 4). Qualitative and quantitative data suggest that epilepsy-related stigma leads to poor overall function, particularly regarding social engagement and employment $[111,114,115]$. Further, increased stigma has been associated with decreased disclosure and discussion about epilepsy [116, 117]. For example, 34\% of married Pakistani women with epilepsy actively concealed their epilepsy diagnosis during marriage negotiations in response to misconceptions regarding their diagnosis, pressure from family members, and to avoid rejection and further stigmatization [118].

Epilepsy-associated stigma has also been shown to affect family members of people with epilepsy. Among mothers of children younger than 8 years with epilepsy, stigma has been associated with increased maternal psychopathology [119]. Mothers were also more likely to actively limit their child's activities based on their own and perceived interpretation of their child's internalized stigma [119].

Epilepsy-related stigma has been associated with social withdrawal and adverse health behaviors such as poor medication adherence [120]. This relationship may be mediated by increased medication side-effects reported among adults with epilepsy [121] as these side-effects have previously been associated with increased stigma $[122,123]$, though this relationship has yet to be formally examined as none of the epilepsy studies included in the review evaluated mediators or moderators.

\section{Substance use}

Stigma is often prevalent among persons who use alcohol or other substances in both the community and in healthcare settings, with possible adverse consequences (Table 5). Among persons using alcohol or other substances, substance-related stigma was identified as a barrier to accessing drug treatment services [124, 125], general healthcare services [124, 126], HIV testing [127, 128], reduced antiretroviral therapy or treatment adherence [129-131], needle exchange programs [132], and to recovery generally [133]. Stigma among persons who use substances was also associated with less education and not being employed full-time [134], as well as lower quality of life across several domains, including the social, physical, psychological, and environmental domains [135], higher risk of relapse [136], social isolation, anxiety, and depression [137]. Healthcare professionals and trainees, including pharmacists and pharmacy students [138], medical students and recent medical graduates [139], and primary healthcare workers [140], expressed stigmatizing beliefs and attitudes towards persons who use drugs.

In addition to stigma occurring as a result of substance use, stigma related to HIV and other health conditions can also be associated with an increased risk for alcohol and other substance misuse. HIV stigma was associated with hazardous/harmful alcohol use among persons co-infected with HIV and TB [141]. Further, among persons with HIV and alcohol use, high levels of HIV-related stigma were associated with increased odds of experiencing physical and sexual violence [142]. Higher levels of HIV stigma were also associated with other (non-alcohol) substance use [143]. Stigma not attached to a health condition can also increase the risk of alcohol and other substance use; indeed, recent discrimination (e.g., based on race, age) was associated with increased odds of both alcohol and drug use [144-146].

Two studies investigated moderators. Years of study at university [145], income, and place of residence were found to be significant moderators of stigma-substance use relationships. One study investigated mediators and found that, among men who have sex with men, alcohol and substance use mediated the relationship between stigma and risky sexual behaviors [147].

\section{Intersectional stigmas}

Stigmatized medical co-morbidities were common across the five conditions. In many LMICs, the prevalence of HIV and TB can be high and the burden of chronic non-infectious disorders like epilepsy, mental illness, and substance use is growing. HIV-related stigma has been associated with harmful alcohol use among individuals with comorbid HIV and TB infection [87] as well as increased (non-alcohol) substance use among individuals with HIV (alone) compared to those without HIV [143]. Stigma due to other marginalized characteristics (sex, race, gender, country of origin, etc.) also increases the risk of substance use and physical and sexual violence [142, 144-146]. This interaction has culminated in a syndemic, with an increased burden of stigma [148]. 
HIV-related stigma has been shown to attenuate the impact of TB-related stigma in some settings [77, 149], while potentiating it in others [150]. Comorbid stigmas do not always result in worse health outcomes. For example, while Zambian adults with HIV and epilepsy endorsed greater stigma, this did not translate into an increased prevalence of depression [151]. However, stigma due to one medical condition, such as substance use, has also been shown to hinder preventative care, including HIV testing [127, 128] and, among individuals with comorbid HIV infection, medication adherence [129-131].

\section{Discussion}

Across disease types included in this scoping review, stigma was associated with poor individual health outcomes and health utilization patterns. Stigmas related to HIV, TB, epilepsy, and substance use were associated with increased psychiatric morbidity, particularly depression and anxiety. Stigma has repeatedly been associated with decreased quality of life and poorer functioning across conditions. Highly stigmatized individuals are more likely to conceal their condition and, as a result, are less likely to seek care or more likely to delay care. This is consistent with the literature from high-income countries on stigma related to mental health conditions. In a systematic review of 144 studies (the vast majority of which were from high income countries) [152], the median effect size of stigma on help-seeking for mental health disorder was -0.27 , though there was some evidence that this relationship was stronger among ethnic minority groups within these countries; qualitative studies suggested that this is both a direct relationship and may be mediated through decreasing disclosure.

Among those obtaining treatment for all five conditions examined in this review, stigma was associated with decreased medication adherence and, among patients with substance use, relapse. In high-income countries, the relationships between treatment adherence and stigma related to mental health problems is varied. Perceived stigma has been found to predict poorer treatment outcomes for individuals with depression [153, 154]; though this evidence is mixed, internalized stigma has also been found to be related to poorer treatment adherence for individuals living with multiple mental health conditions [155]. Conversely, anticipated and experienced discrimination has been found to not be significantly associated with antipsychotic medication adherence for people living with schizophrenia [156].

Studies examining individuals with multiple stigmatized conditions suggest that the effects of health-related stigma can be felt across all domains. Just as stigma among individuals with mental health problems or injection drug use decreases their use of mental health and substance disorder services, it also decreases HIV testing and medication adherence. Unfortunately, the effects of stigma across conditions are complex and, similar to studies describing stigma in high-income countries [1], our review found that studies of stigma and health outcomes in LMICs are largely focused on one stigmatizing condition (often only internalized stigma) and one health outcome. Few studies described the complex interactions between different types of stigma and the co-occurring health conditions likely to be present.

As highlighted in Boxes 1, 2 and 3, the review results showed that marginalized members of society are increasingly vulnerable to health-related stigma. LGBTQ individuals, racial and ethnic minorities, and refugees suffer from increased stigma due to lack of social and economic stability, fear of encountering stigma, and increased self-stigmatization. Unequal access to treatment and, among refugee communities, decreased access to information, result in reduced healthcare-seeking behaviors. These associations can be amplified by perceived stigma from the healthcare community, which further delays care and reduces healthcare-seeking behavior. The effects of trauma, particularly among LGBTQ individuals and refugees, are often under-recognized, which also affects care. Unfortunately, as most studies recruit participants from healthcare settings, these individuals may have been overlooked within the available stigma data, and particularly in that related to HIV, mental health, and epilepsy. Similarly, difficulty in recruiting these populations presents a research challenge and affects data availability. Therefore, the effect of stigma on the health and health outcomes of vulnerable populations may be underestimated. While the substance use literature featured a wider range of populations, including representation of sexual and gender minorities, as well as geographies, the generalizability of this data is limited by its focus on alcohol and injection drug use; other substance types (e.g., inhalants, cocaine, prescription drugs) that may have associations with stigma have been largely neglected. Further, the effect of stigma on child and adolescent populations is poorly understood as only one study examining epilepsy-associated stigma focused on this vulnerable population [107]. Given that risk factors, symptom presentation, and trajectories of mental health and substance use problems may vary across the life course, increased research on stigma among children and adolescents is essential.

Comprehensive, multidisciplinary stigma-focused prevention and treatment approaches are warranted in LMICs. However, the design and implementation of these interventions is limited by the data available. This review highlights the paucity of longitudinal stigma studies on health-related stigma in LMICs, particularly among community-based samples, which limits our understanding of the mechanisms by which stigma impacts 
health outcomes. Appropriately designed quantitative cohort studies are vital to addressing these issues. Further, most of the studies included in this review were limited by small sample size and, as a result, data regarding mediators of the association between stigma and health outcomes is scant. Future research should include larger sample sizes that would enable more complex path modelling, including effect modification analysis. Available data suggests that gender is a moderator of both TB-related and substance use stigma. Understanding the effects of moderators and mediators on the relationship of stigma with individual health outcomes will improve the effectiveness of stigma reduction interventions.

\section{Limitations of the review}

The purpose of the review was to inform both potential future research studies and possible research questions that could be addressed by systematic reviews. Formal study inclusion and exclusion criteria were not used as the review was not systematic; however, similar search terms and databases were used across the five disease reviews. Although the types of study designs described in the literature were often noted, individual study quality was not assessed, as is typical in scoping reviews. Finally, we focused on five disease/disorders that significantly drive the disease burden in LMICs. Future reviews should focus on other stigmatized conditions affecting individuals in this setting, including abortion, cancer, leprosy, albinism, gender identity, sex work, sexual violence, and sexually transmitted infections.

\section{Conclusion}

A rapidly growing body of literature, mostly qualitative and cross-sectional in design, suggests that stigma is associated with poor health outcomes, including less help-seeking, among persons with HIV, TB, mental health, neurologic disorders, and substance use. This review highlights consistencies in the relationship of stigma with health outcomes, but also common methodological limitations. Future studies can address these limitations by (1) recognizing that comorbidity is the rule and not the exception and that the complex interconnected relationships between stigma and multiple health outcomes must be accounted for in the study design phase; (2) measuring multiple types of stigma at multiple health outcome levels; and (3) featuring longitudinal designs, investigation into mediators and moderators, and community-based study samples to improve generalizability. Removing the siloes from health-related stigma research in LMICs and addressing these limitations will improve the epidemiological literature on evidence-based stigma interventions, ultimately improving outcomes associated with high-burden diseases.

\section{Additional file}

Additional file 1: Full list of search terms for each database searched. (DOCX $39 \mathrm{~kb})$

\section{Abbreviations}

DRTB: drug-resistant tuberculosis; LGBTQ: lesbian, gay, bisexual, transgender, queer; LMICs: low- and middle-income countries; TB: tuberculosis

\section{Acknowledgments}

This article is part of a collection that draws upon a 2017 workshop on stigma research and global health, which was organized by the Fogarty International Center, National Institute of Health, United States. The article was supported by a generous contribution by the Fogarty International Center. The authors thank Gretchen Birbeck, Virginia Bond, Valerie Earnshaw, and Musah Lumumba for their helpful comments on the manuscript.

\section{Funding}

The publication of this paper was supported by the Fogarty International Center of the National Institutes of Health. Efforts by JCK, SMM, and SDB were supported in part by the National Institutes of Mental Health and Office of AIDS Research of the National Institutes of Health under award number R01MH110358. This publication was also supported with help from the Johns Hopkins University Center for AIDS Research, an NIH funded program (P30Al094189), which is funded by the following NIH Institutes and Centers: NIAID, NCI, NICHD, NHLBI, NIDA, NIMH, NIA, FIC, NIGMS, NIDDK, and OAR. The content is solely the responsibility of the authors and does not necessarily represent the official views of the $\mathrm{NIH}$.

\section{Availability of data and materials}

The data used and/or analyzed are provided in the associated tables and supplementary material.

\section{Authors' contributions}

JCK and SDB conceptualized the paper. Reviews were conducted and drafted by MAE (HIV and epilepsy), EMHM (tuberculosis), SMM (mental health), JCK (substance use), and SC (populations of concern). JLA wrote the first draft of the Background section; JCK wrote the first draft of the Discussion. All authors contributed to interpretation of review findings and drafting the Conclusion section. All authors read and approved the final manuscript.

\section{Authors' information}

JCK is Assistant Scientist, SMM is an Assistant Professor, and JLA is a postdoctoral research fellow in the Department of Mental Health at Johns Hopkins Bloomberg School of Public Health (JHSPH). SDB is Associate Professor in the Department of Epidemiology at JHSPH. MAE is a resident physician in the Department of Neurology at Johns Hopkins University. EMHM is a senior epidemiologist with the KNCV Tuberculosis Foundation. SC is a PhD student at the Department of Public Health Sciences at Karolinska Institutet.

Ethics approval and consent to participate Not applicable.

\section{Consent for publication}

Not applicable.

\section{Competing interests}

The authors declare that they have no competing interests.

\section{Publisher's Note}

Springer Nature remains neutral with regard to jurisdictional claims in published maps and institutional affiliations.

\section{Author details}

'Department of Mental Health, Johns Hopkins Bloomberg School of Public Health, 624 North Broadway, Baltimore, MD 21205, USA. ²Department of Neurology, Johns Hopkins School of Medicine, Sheikh Zayed Tower, Room 6005, 1800 Orleans Street, Baltimore, MD 21205, USA. International Institute 
for Social Studies, Erasmus University, Kortenaerkade 12, 2518 AX The Hague, Netherlands. ${ }^{4}$ Department of Public Health Sciences, Karolinska Institutet, Widerströmska huset, Tomtebodavägen 18A, 17177 Stockholm, Sweden. ${ }^{5}$ Department of Epidemiology, Johns Hopkins Bloomberg School of Public Health, 615 N. Wolfe Street, Baltimore, MD 21205, USA.

Received: 5 June 2018 Accepted: 2 January 2019

Published online: 15 February 2019

\section{References}

1. Hatzenbuehler ML, Phelan JC, Link BG. Stigma as a fundamental cause of population health inequalities. Am J Public Health. 2013;103:813-21.

2. World Health Organization. Mental health Problems: The Undefined and Hidden Burden. Geneva: WHO; 2001. https://www.who.int/mediacentre/ factsheets/fs218/en/. Accessed 19 Dec 2018

3. Scrambler G, Hopkins A. Beign epileptic: coming to terms with stigma Sociol Heal IIIn. 1987:8:26-43.

4. Link BG. Understanding labeling effects in the area of mental disorders: an assessment of the effects of expectations of rejection. Am Sociol Rev. 1987; $52: 96$

5. Earnshaw VA, Smith LR, Shuper PA, Fisher WA, Cornman DH, Fisher JD. HIV stigma and unprotected sex among PLWH in KwaZulu-Natal, South Africa: a longitudinal exploration of mediating mechanisms. AIDS Care. 2014;26: 1506-13.

6. Zelaya CE, Sivaram S, Johnson SC, Srikrishnan AK, Suniti S, Celentano DD Measurement of self, experienced, and perceived HIV/AIDS stigma using parallel scales in Chennai, India. AIDS Care. 2012;24:846-55.

7. Earnshaw VA, Smith LR, Chaudoir SR, Amico KR, Copenhaver MM. HIV stigma mechanisms and well-being among PLWH: a test of the HIV stigma framework. AIDS Behav. 2013;17:1785-95.

8. Muñoz M, Sanz M, Pérez-Santos E, Quiroga M de I Á. Proposal of a sociocognitive-behavioral structural equation model of internalized stigma in people with severe and persistent mental illness. Psychiatry Res. 2011;186: 402-8.

9. Sheehan L, Nieweglowski K, Corrigan P. Structures and types of stigma. In: Gaebel W, Roessler W, Sartorius N, editors. The Stigma of Mental Illness End of the Story? New York: Springer; 2017.

10. Phillips KD, Moneyham L, Tavakoli A. Development of an instrument to measure internalized stigma in those with HIV/AIDS. Issues Ment Health Nurs. 2011;32:359-66.

11. Catona D, Greene K, Magsamen-Conrad K, Carpenter A. Perceived and experienced stigma among people living with HIV: examining the role of prior stigmatization on reasons for and against future disclosures. J Appl Commun Res. 2016;44:136-55.

12. Weiss MG. Stigma and the social burden of neglected tropical diseases. PLoS Negl Trop Dis. 2008;2:e237.

13. UNAIDS. Confronting Discrimination: Overcoming HIV-related Stigma and Discriminiation in Health-care Settings and Beyond. Geneva: UNAIDS; 2017.

14. Petros G, Airhihenbuwa CO, Simbayi L, Ramlagan S, Brown B. HIV/AIDS and 'othering' in South Africa: the blame goes on. Cult Health Sex. 2006;8:67-77.

15. Stringer KL, Baker EH. Stigma as a barrier to substance abuse treatment among those with unmet need: an analysis of parenthood and marital status. J Fam Issues. 2018;39:3-27.

16. Demyttenaere K, Bruffaerts R, Posada-Villa J, Gasquet I, Kovess V, Lepine JP, et al. Prevalence, severity, and unmet need for treatment of mental disorders in the World Health Organization World Mental Health Surveys. JAMA. 2004;291:2581-90.

17. Mugglin C, Estill J, Wandeler G, Bender N, Egger M, Gsponer T, et al. Loss to programme between HIV diagnosis and initiation of antiretroviral therapy in sub-Saharan Africa: systematic review and meta-analysis. Trop Med Int Heal. 2012;17:1509-20.

18. Meyer A-CL, Dua T, Boscardin WJ, Escarce JJ, Saxena S, Birbeck GL. Critical determinants of the epilepsy treatment gap: a cross-national analysis in resource-limited settings. Epilepsia. 2012;53:2178-85.

19. Rueda S, Mitra S, Chen S, Gogolishvili D, Globerman J, Chambers L, et al. Examining the associations between HIV-related stigma and health outcomes in people living with HIV/AIDS: a series of meta-analyses. BM Open. 2016;6:e011453.

20. Mula M, Sander JW. Psychosocial aspects of epilepsy: a wider approach. BJPsych Open. 2016;2:270-4.
21. Arksey H, O'Malley L. Scoping studies: towards a methodological framework. Int J Soc Res Methodol. 2005:8:19-32.

22. Armstrong R, Hall BJ, Doyle J, Waters E. "Scoping the scope" of a cochrane review. J Public Health. 2011:33:147-50.

23. Zhang L, Li X, Qiao S, Zhou Y, Shen Z, Tang Z, et al. The mediating role of individual resilience resources in stigma-health relationship among people living with HIV in Guangxi, China. AIDS Care. 2015;27:1317-25.

24. Kingori C, Reece M, Obeng S, Murray M, Shacham E, Dodge B, et al. Impact of internalized stigma on HIV prevention behaviors among HIV-infected individuals seeking HIV care in Kenya. AIDS Patient Care STDS. 2012;26:761-8.

25. Peitzmeier SM, Grosso A, Bowes A, Ceesay N, Baral SD. Associations of stigma with negative health outcomes for people living with HIV in the Gambia. J Acquir Immune Defic Syndr. 2015;68:S146-53.

26. Calabrese SK, Burke SE, Dovidio JF, Levina OS, Uusküla A, Niccolai LM, et al. Internalized HIV and drug stigmas: interacting forces threatening health status and health service utilization among people with HIV who inject drugs in St. Petersburg, Russia. AIDS Behav. 2016;20:85-97.

27. Yi S, Chhoun P, Suong S, Thin K, Brody C, Tuot S. AIDS-related stigma and mental disorders among people living with HIV: a cross-sectional study in Cambodia. PLoS One. 2015;10:e0121461.

28. Dow DE, Turner EL, Shayo AM, Mmbaga B, Cunningham CK, O'Donnell K. Evaluating mental health difficulties and associated outcomes among HIVpositive adolescents in Tanzania. AIDS Care. 2016;28(7):825-33.

29. Deribew A, Tesfaye M, Hailmichael Y, Apers L, Abebe G, Duchateau L, et al. Common mental disorders in TB/HIV co-infected patients in Ethiopia. BMC Infect Dis. 2010;10:201.

30. Endeshaw M, Walson J, Rawlins S, Dessie A, Alemu S, Andrews N, et al. Stigma in Ethiopia: association with depressive symptoms in people with HIV. AIDS Care. 2014;26:935-9.

31. Kalomo EN. Associations between HIV-related stigma, self-esteem, social support, and depressive symptoms in Namibia. Aging Ment Health. 2017. https://doi.org/10.1080/13607863.2017.1387763.

32. Zhang C, Li X, Liu Y, Qiao S, Zhou Y, Shen Z, et al. Substance use and psychosocial status among people living with HIV/AIDS who encountered HIV stigma in China: stratified analyses by socio-economic status. PLoS One. 2016;11:e0165624.

33. Li L, Lee S-J, Thammawijaya P, Jiraphongsa C, Rotheram-Borus MJ. Stigma, social support, and depression among people living with HIV in Thailand. AIDS Care. 2009;21:1007-13.

34. Mohite VR, Mohite RV, George J. Correlates of perceived stigma and depression among the women with HIV/AIDS infection. Bangladesh J Med Sci. 2015;14:151.

35. Li J, Mo PKH, Wu AMS, Lau JTF. Roles of self-stigma, social support, and positive and negative affects as determinants of depressive symptoms among HIV infected men who have sex with men in China. AIDS Behav. 2017;21:261-73

36. Breet E, Kagee A, Seedat S. HIV-related stigma and symptoms of posttraumatic stress disorder and depression in HIV-infected individuals: does social support play a mediating or moderating role? AIDS Care. 2014;26: 947-51.

37. Rael CT, Davis A. Depression and key associated factors in female sex workers and women living with HIV/AIDS in the Dominican Republic. Int $J$ STD AIDS. 2017:28:433-40.

38. Shrestha R, Copenhaver M, Bazazi AR, Huedo-Medina TB, Krishnan A, Altice FL. A moderated mediation model of HIV-related stigma, depression, and social support on health-related quality of life among incarcerated Malaysian men with HIV and opioid dependence. AIDS Behav. 2017;21: 1059-69.

39. Tao J, Wang L, Kipp AM, Qian H-Z, Yin L, Ruan Y, et al. Relationship of stigma and depression among newly HIV-diagnosed Chinese men who have sex with men. AIDS Behav. 2017;21:292-9.

40. Wu DY, Munoz M, Espiritu B, Zeladita J, Sanchez E, Callacna M, et al. Burden of depression among impoverished HIV-positive women in Peru. J Acquir Immune Defic Syndr. 2008:48:500-4.

41. Liu Y, Gong H, Yang G, Yan J. Perceived stigma, mental health and unsafe sexual behaviors of people living with HIV/AIDS. Zhong Nan Da Xue Xue Bao Yi Xue Ban. 2014;39:658-63.

42. Tesfaw G, Ayano G, Awoke T, Assefa D, Birhanu Z, Miheretie G, et al. Prevalence and correlates of depression and anxiety among patients with HIV on-follow up at Alert Hospital, Addis Ababa, Ethiopia. BMC Psychiatry. 2016;16:368 
43. Olley B, Adebayo K, Ogunde M, Ishola A, Ogar A. Psychosocial factors predicting severity of depression among treatment-seeking HIV/AIDS patients: a multi-site Nigerian study. Niger J Clin Pract. 2017;20:296.

44. Robinson A, Malcolm S. P14.16 Self reported hiv discrimination and willingness to disclose hiv seropositivity among a sample of turks and caicos islanders. Sex Transm Infect. 2015:91:A204.1.

45. Tsai AC, Bangsberg DR, Kegeles SM, Katz IT, Haberer JE, Muzoora C, et al. Internalized stigma, social distance, and disclosure of HIV seropositivity in rural Uganda. Ann Behav Med. 2013;46:285-94.

46. Olley BO, Ogunde MJ, Oso PO, Ishola A. HIV-related stigma and self-disclosure: the mediating and moderating role of anticipated discrimination among people living with HIV/AIDS in Akure Nigeria. AIDS Care. 2016;28:726-30.

47. Colombini M, Mutemwa R, Kivunaga J, Stackpool Moore L, Mayhew SH, Integra Initiative. Experiences of stigma among women living with HIV attending sexual and reproductive health services in Kenya: a qualitative study. BMC Health Serv Res. 2014;14:412.

48. Makin JD, Forsyth BWC, Visser MJ, Sikkema KJ, Neufeld S, Jeffery B. Factors affecting disclosure in South African HIV-positive pregnant women. AIDS Patient Care STDS. 2008;22:907-16.

49. Ojikutu BO, Pathak S, Srithanaviboonchai K, Limbada M, Friedman R, Li S, et al. Community cultural norms, stigma and disclosure to sexual partners among women living with HIV in Thailand, Brazil and Zambia (HPTN 063). PLoS One. 2016;11:e0153600.

50. Lyimo RA, Stutterheim SE, Hospers HJ, de Glee T, van der Ven A, de Bruin M. Stigma, disclosure, coping, and medication adherence among people living with HIV/AIDS in Northern Tanzania. AIDS Patient Care STDS. 2014;28: 98-105.

51. Valenzuela C, Ugarte-Gil C, Paz J, Echevarria J, Gotuzzo E, Vermund SH, et al. HIV stigma as a barrier to retention in HIV care at a general hospital in Lima, Peru: a case-control study. AIDS Behav. 2015;19:235-45.

52. Valencia-Garcia D, Rao D, Strick L, Simoni JM. Women's experiences with HIV-related stigma from health care providers in Lima, Peru: "I would rather die than go back for care.". Health Care Women Int. 2017;38:144-58.

53. Carlucci JG, Kamanga A, Sheneberger R, Shepherd BE, Jenkins CA, Spurrier J, et al. Predictors of adherence to antiretroviral therapy in rural Zambia. J Acquir Immune Defic Syndr. 2008;47:615-22

54. Dlamini PS, Wantland D, Makoae LN, Chirwa M, Kohi TW, Greeff M, et al. HIV stigma and missed medications in HIV-positive people in five African countries. AIDS Patient Care STDS. 2009;23:377-87.

55. Erku DA, Mekuria AB, Gebresillassie BM. Perceived HIV stigma as a barrier to sustained ART adherence in North West Ethiopia: a cohort study. Value Heal. 2016;19:A219.

56. Bitew H, Andargie G, Tadesse A, Belete A, Fekadu W, Mekonen T. Suicidal ideation, attempt, and determining factors among HIV/AIDS patients, Ethiopia. Depress Res Treat. 2016;2016:8913160.

57. Rodriguez VJ, Cook RR, Peltzer K, Jones DL. Prevalence and psychosocial correlates of suicidal ideation among pregnant women living with HIV in Mpumalanga Province, South Africa. AIDS Care. 2017;29:593-7.

58. Zhou G, Li X, Qiao S, Shen Z, Zhou Y. HIV symptom management selfefficacy mediates the relationship of internalized stigma and quality of life among people living with HIV in China. J Health Psychol. 2017. https://doi. org/10.1177/1359105317715077.

59. Abboud S, Noureddine S, Huijer HA-S, DeJong J, Mokhbat J. Quality of life in people living with HIV/AIDS in Lebanon. AIDS Care. 2010;22:687-96.

60. Holzemer WL, Human S, Arudo J, Rosa ME, Hamilton MJ, Corless I, et al. Exploring HIV stigma and quality of life for persons living with HIV infection. J Assoc Nurses AIDS Care. 2009;20:161-8.

61. Tesfay A, Gebremariam A, Gerbaba M, Abrha H. Gender differences in health related quality of life among people living with HIV on highly active antiretroviral therapy in Mekelle Town, Northern Ethiopia. BioMed Res Int. 2015;2015:516369.

62. Steward WT, Herek GM, Ramakrishna J, Bharat S, Chandy S, Wrubel J, et al. HIV-related stigma: adapting a theoretical framework for use in India. Soc Sci Med. 2008:67:1225-35.

63. Kurspahić-mujčić A, Hasanović A, Sivić S. Tuberculosis related stigma and delay in seeking care after the onset of symptoms associated with tuberculosis. Med Glas. 2013;10:272-7.

64. Rajeswari R, Chandrasekaran V, Suhadev M, Sivasubramaniam S, Sudha G, Renu G. Factors associated with patient and health system delays in the diagnosis of tuberculosis in South India. Int J Tuberc Lung Dis. 2002;6:789-95.
65. Somma D, Thomas BE, Karim F, et al. Gender and socio-cultural determinants of TB-related stigma in Bangladesh, India, Malawi and Colombia [Special section on gender and TB]. Int J Tuberc Lung Dis. 2008;12:856-66.

66. Coreil J, Mayard G, Simpson KM, Lauzardo M, Zhu Y, Weiss M. Structural forces and the production of TB-related stigma among Haitians in two contexts. Soc Sci Med. 2010;71:1409-17.

67. Courtwright A, Turner AN. Tuberculosis and stigmatization: pathways and interventions. Public Health Rep. 2010;125(Suppl):34-42.

68. Sweetland AC, Kritski A, Oquendo MA, Sublette ME, Norcini Pala A, Silva LRB, et al. Addressing the tuberculosis-depression syndemic to end the tuberculosis epidemic. Int J Tuberc Lung Dis. 2017;21:852-61.

69. Xu M, Markström U, Lyu J, Xu L. Survey on tuberculosis patients in rural areas in China: tracing the role of stigma in psychological distress. Int J Environ Res Public Health. 2017;14(10):pii:E1171.

70. Dodor EA, Kelly S, Neal K. Health professionals as stigmatisers of tuberculosis: Insights from community members and patients with TB in an urban district in Ghana. Psychol Health Med. 2009;14:301-10.

71. Wouters E, Rau A, Engelbrecht M, Uebel K, Siegel J, Masquillier C, et al. The development and piloting of parallel scales measuring external and internal HIV and tuberculosis stigma among healthcare workers in the Free State Province, South Africa. Clin Infect Dis. 2016;62(Suppl 3):S244-54.

72. Kipp AM, Pungrassami P, Nilmanat K, Sengupta S, Poole C, Strauss RP, et al. Socio-demographic and AIDS-related factors associated with tuberculosis stigma in southern Thailand: a quantitative, cross-sectional study of stigma among patients with TB and healthy community members. BMC Public Health. 2011;11:675

73. Méda ZC, Lin Y-T, Sombié I, Maré D, Morisky DE, Chen Y-MA. Medicationadherence predictors among patients with tuberculosis or human immunodeficiency virus infection in Burkina Faso. J Microbiol Immunol Infect. 2014:47:222-32.

74. Ogundele OA, Moodley D, Pillay AW, Seebregts CJ. An ontology for factors affecting tuberculosis treatment adherence behavior in sub-Saharan Africa. Patient Prefer Adherence. 2016;10:669-81.

75. Yan S, Zhang S, Tong Y, Yin X, Lu Z, Gong Y. Nonadherence to antituberculosis medications: the impact of stigma and depressive symptoms. Am J Trop Med Hyg. 2018;98(1):262-5.

76. Hassard S, Ronald A, Angella K. Patient attitudes towards community-based tuberculosis DOT and adherence to treatment in an urban setting; Kampala, Uganda. Pan Afr Med J. 2017;27:1-6.

77. Kipp AM, Pungrassami P, Stewart PW, Chongsuvivatwong V, Strauss RP, Van Rie A. Study of tuberculosis and AIDS stigma as barriers to tuberculosis treatment adherence using validated stigma scales. Int J Tuberc Lung Dis. 2011;15:1540-6

78. Mason P, Singh P, Ho J, Anh N, Fox G, Marks G. Coping Self-efficacy for TB Treatment in Ca Mau, Vietnam. Sydney, Australia: 5th Conference of The Union Asia-Pacific Region; 2015.

79. Daftary A, Padayatchi N, O'Donnell M. Preferential adherence to antiretroviral therapy over tuberculosis treatment: a qualitative study of drug-resistant TB/HIV co-infected patients in South Africa. Glob Public Health. 2014;9:1107-16.

80. Macintyre K, Bakker MI, Bergson S, Bhavaraju R, Bond V, Chikovore J, et al. Defining the research agenda to measure and reduce tuberculosis stigmas. Int J Tuberc Lung Dis. 2017;21:87-96.

81. Isaakidis P, Rangan S, Pradhan A, Ladomirska J, Reid T, Kielmann K. "I cry every day": experiences of patients co-infected with HIV and multidrugresistant tuberculosis. Trop Med Int Health. 2013;18:1128-33.

82. O'Donnell MR, Wolf A, Werner L, Horsburgh CR, Padayatchi N. Adherence in the treatment of patients with extensively drug-resistant tuberculosis and HIV in South Africa: a prospective cohort study. J Acquir Immune Defic Syndr. 2014;67:22-9.

83. Atre S, Kudale A, Morankar S, Gosoniu D, Weiss MG. Gender and community views of stigma and tuberculosis in rural Maharashtra, India. Glob Public Health. 2011;6:56-71.

84. Dhuria M, Sharma N. Narender Pal Singh, Ram Chander Jiloha, Saha R, Gopal Krishan Ingle. A study of the impact of tuberculosis on the quality of life and the effect after treatment with DOTS. Asia Pacific J Public Heal. 2009;21:312-20.

85. Sima BT, Belachew T, Abebe F. Knowledge, attitude and perceived stigma towards tuberculosis among pastoralists; Do they differ from sedentary communities? A comparative cross-sectional study. PLoS One. 2017;12: e0181032. 
86. Li SP, Zheng ZY, Meng QY, Yuan CH. Barriers to tuberculosis care for drug users in two provinces of China: a qualitative study. Int J Tuberc Lung Dis. 2013;17:1358-63

87. Hayes-Larson E, Hirsh-Moverman Y, Saeto S, Koen F, Pitt B, Maama-Maime L, et al. High baseline prevalence of stigma, depressive symptoms and hazardous alcohol use among TB/HIV patients in Lesotho. Int J Tuberc Lung Dis. 2017;21(11):34-41.

88. Li J, Guo Y-B, Huang Y-G, Liu J-W, Chen W, Zhang X-Y, et al. Stigma and discrimination experienced by people with schizophrenia living in the community in Guangzhou, China. Psychiatry Res. 2017;255:225-31.

89. Singh A, Mattoo SK, Grover S. Stigma and its correlates in patients with schizophrenia attending a general hospital psychiatric unit. Indian J Psychiatry. 2016;58:291-300.

90. Shi-Jie F, Hong-Mei G, Li W, Bin-Hong W, Yi-Ru F, Gang W, et al. Perceptions of stigma and its correlates among patients with major depressive disorder: a multicenter survey from China. Asia-Pac Psychiatry. 2017;9:e12260. https:// doi.org/10.1111/appy.12260.

91. Fawzi MH, Said NS, Fawzi MM, Kira IA, Fawzi MM, Abdel-Moety H. Psychiatric referral and glycemic control of Egyptian type 2 diabetes mellitus patients with depression. Gen Hosp Psychiatry. 2016;40:60-7.

92. Elkington KS, McKinnon K, Mann CG, Collins PY, Leu C-S, Wainberg ML. Perceived mental illness stigma and HIV risk behaviors among adult psychiatric outpatients in Rio de Janeiro, Brazil. Community Ment Health J. 2010;46:56-64.

93. Assefa D, Shibre T, Asher L, Fekadu A. Internalized stigma among patients with schizophrenia in Ethiopia: a cross-sectional facility-based study. BMC Psychiatry. 2012;12:239.

94. Adewuya AO, Owoeye OA, Erinfolami AR, Coker AO, Ogun OC, Okewole AO, et al. Prevalence and correlates of poor medication adherence amongst psychiatric outpatients in southwestern Nigeria. Gen Hosp Psychiatry. 2009; 31:167-74.

95. Bifftu BB, Dachew BA. Perceived stigma and associated factors among people with Schizophrenia at Amanuel Mental Specialized Hospital, Addis Ababa, Ethiopia: a cross-sectional institution based study. Psychiatry J. 2014; 2014:694565.

96. Roberts B, Makhashvili N, Javakhishvili J, Karachevskyy A, Kharchenko N, Shpiker $\mathrm{M}$, et al. Mental health care utilisation among internally displaced persons in Ukraine: results from a nation-wide survey. Epidemiol Psychiatr Sci. 2017. https://doi.org/10.1017/S20457960170.

97. Lahariya C, Singhal S, Gupta S, Mishra A. Pathway of care among psychiatric patients attending a mental health institution in central India. Indian J Psychiatry. 2010;52:333-8.

98. Mosanya TJ, Adelufosi AO, Adebowale OT, Ogunwale A, Adebayo OK. Selfstigma, quality of life and schizophrenia: an outpatient clinic survey in Nigeria. Int J Soc Psychiatry. 2014;60:377-86.

99. Grover S, Avasthi A, Singh A, Dan A, Neogi R, Kaur D, et al. Stigma experienced by patients with severe mental disorders: a nationwide multicentric study from India. Psychiatry Res. 2017;257:550-8.

100. LV Y, Wolf $A$, Wang $X$. Experienced stigma and self-stigma in Chinese patients with schizophrenia. Gen Hosp Psychiatry. 2013;35:83-8.

101. Koschorke M, Padmavati R, Kumar S, Cohen A, Weiss HA, Chatterjee S, et al. Experiences of stigma and discrimination of people with schizophrenia in India. Soc Sci Med. 2014;123:149-59.

102. Kulesza M, Raguram R, Rao D. Perceived mental health related stigma, gender, and depressive symptom severity in a psychiatric facility in South India. Asian J Psychiatr. 2014;9:73-7.

103. Rayan A, Mahroum MH, Khasawneh A. The correlates of stigma toward mental illness among Jordanian patients with major depressive disorder Perspect Psychiatr Care. 2018;54(2):192-7.

104. Rayan A, Obiedate K. The correlates of quality of life among Jordanian patients with schizophrenia. J Am Psychiatr Nurses Assoc. 2017;23:404-13.

105. Xu Z-Y, Zu S, Xiang Y-T, Wang N, Guo Z-H, Kilbourne AM, et al. Associations of self-esteem, dysfunctional beliefs and coping style with depression in patients with schizophrenia: A preliminary survey. Psychiatry Res. 2013;209:340-5.

106. Dardas LA, Silva SG, van de Water B, Vance A, Smoski MJ, Noonan D, et al. Psychosocial correlates of Jordanian adolescents' help-seeking intentions for depression: findings from a nationally representative school survey. J Sch Nurs. 2017:105984051773149. https://doi.org/10.1177/1059840517731493.

107. Sharaf AY, Ossman LH, Lachine OA. A cross-sectional study of the relationships between illness insight, internalized stigma, and suicide risk in individuals with schizophrenia. Int J Nurs Stud. 2012;49:1512-20.
108. Choi E-J, Lee S-A, Jo K-D, Yim S-B, No Y-J, Kwon J-H, et al. Factors contributing to concerns of persons living with epilepsy. Seizure. 2011; 20:14-7.

109. Hirfanoglu T, Serdaroglu A, Cansu A, Soysal AS, Derle E, Gucuyener K. Do knowledge of, perception of, and attitudes toward epilepsy affect the quality of life of Turkish children with epilepsy and their parents? Epilepsy Behav. 2009;14:71-7.

110. Turki M, Bouchhima I, Halouani N, Turki E, Bouzidi N, Dammak M, et al. Epilepsy and self-esteem. Eur Psychiatry. 2016;33:S384-5.

111. Yeni K, Tulek Z, Bebek N, Dede O, Gurses C, Baykan B, et al. Attitudes towards epilepsy among a sample of Turkish patients with epilepsy. Epilepsy Behav. 2016;62:66-71.

112. Doganavsargil-Baysal O, Cinemre B, Senol Y, Barcin E, Gokmen Z. Epilepsy and stigmatization in Turkey. Epilepsy Behav. 2017;73:100-5.

113. Han SH, Kim B, Koh EJ, Kim MK, Shin DJ, Lee JY, et al. Family factors contributing to depression in people with epilepsy. Epilepsy Curr. 2015; 15:98-9.

114. Espínola-Nadurille M, Crail-Melendez D, Sánchez-Guzmán MA. Stigma experience of people with epilepsy in Mexico and views of health care providers. Epilepsy Behav. 2014;32:162-9.

115. Fawale MB, Owolabi MO, Ogunniyi A. Effects of seizure severity and seizure freedom on the health-related quality of life of an African population of people with epilepsy. Epilepsy Behav. 2014;32:9-14.

116. Luna J, Nizard M, Becker D, Gerard D, Cruz A, Ratsimbazafy V, et al. Epilepsyassociated levels of perceived stigma, their associations with treatment, and related factors: a cross-sectional study in urban and rural areas in Ecuador. Epilepsy Behav. 2017;68:71-7.

117. Aydemir N, Özkara Ç, Ünsal P, Canbeyli R. A comparative study of health related quality of life, psychological well-being, impact of illness and stigma in epilepsy and migraine. Seizure. 2011;20:679-85.

118. Erum L, Fauziya A, Mughis S, Asho A, Nasreen S. Consequences of premarriage disclosure or concealment of epilepsy disorder the marital lives of women in Karachi, Pakistan. Int J Nurs Care. 2015;3:84-8.

119. Elafros MA, Sakubita-Simasiku C, Atadzhanov M, Haworth A, Chomba E, Birbeck GL. Stigma and psychiatric morbidity among mothers of children with epilepsy in Zambia. Int Health. 2013;5(4):288-94.

120. Getnet A, Woldeyohannes SM, Bekana L, Mekonen T, Fekadu W, Menberu $M$, et al. Antiepileptic drug nonadherence and its predictors among people with epilepsy. Behav Neurol. 2016;2016:3189108.

121. Viteva E. Relation of perceived stigma to adverse events of medications in patients with epilepsy. Epilepsy Res Treat. 2016;2016:5362806.

122. Baker GA, Brooks J, Buck D, Jacoby A. The stigma of epilepsy: a European perspective. Epilepsia. 2000;41:98-104.

123. Taylor J, Baker GA, Jacoby A. Levels of epilepsy stigma in an incident population and associated factors. Epilepsy Behav. 2011;21:255-60.

124. Howard BN, Van Dorn R, Myers BJ, Zule WA, Browne FA, Carney T, et al. Barriers and facilitators to implementing an evidence-based woman-focused intervention in South African health services. BMC Health Serv Res. 2017;17:746

125. Jamshidimanesh M, Mousavi SA, Merghati-Khoei E, Emamian MH, Keramat A. Sexual risk behaviors constructed in Iranian women's life with substance use disorders: a new implication of human ecological theory. Addict Heal. 2016;8:157-69.

126. Lan C-W, Lin C, Thanh DC, Li L. Drug-related stigma and access to care among people who inject drugs in Vietnam. Drug Alcohol Rev. 2018;37(3): 333-9.

127. Du J, Lombardi C, Evans E, Jiang $H$, Zhao M, Meng $Y-Y$. A mixed methods approach to identifying factors related to voluntary HIV testing among injection drug users in Shanghai, China. Int J Infect Dis. 2012;16:e498-503.

128. Ti L, Hayashi K, Kaplan K, Suwannawong P, Wood E, Montaner J, et al. HIV test avoidance among people who inject drugs in Thailand. AIDS Behav. 2013:17:2474-8.

129. Schensul SL, Ha T, Schensul JJ, Vaz M, Singh R, Burleson JA, et al. The role of alcohol on antiretroviral therapy adherence among persons living with HIV in urban India. J Stud Alcohol Drugs. 2017;78:716-24.

130. Mimiaga MJ, Safren SA, Dvoryak S, Reisner SL, Needle R, Woody G. "We fear the police, and the police fear us": structural and individual barriers and facilitators to HIV medication adherence among injection drug users in Kiev, Ukraine. AIDS Care. 2010;22:1305-13.

131. Kekwaletswe CT, Morojele NK. Patterns and predictors of antiretroviral therapy use among alcohol drinkers at HIV clinics in Tshwane, South Africa. AIDS Care. 2014;26(Suppl 1):S78-82. 
132. Deryabina A, El-Sadr WM. Uptake of needle and syringe program services in the Kyrgyz Republic: key barriers and facilitators. Drug Alcohol Depend. 2017;179:180-6.

133. Mora-Rios J, Ortega-Ortega M, Medina-Mora ME. Addiction-related stigma and discrimination: a qualitative study in treatment centers in Mexico City. Subst Use Misuse. 2017:52:594-603.

134. Lim T, Zelaya C, Latkin C, Quan VM, Frangakis C, Ha TV, et al. Individual-level socioeconomic status and community-level inequality as determinants of stigma towards persons living with HIV who inject drugs in Thai Nguyen, Vietnam. J Int AIDS Soc. 2013;16:18637.

135. Sarkar S, Balhara YPS, Kumar S, Saini V, Kamran A, Patil V, et al. Internalized stigma among patients with substance use disorders at a tertiary care center in India. J Ethn Subst Abuse. 2017. https://doi.org/10.1080/15332640. 2017.1357158

136. Yang M, Mamy J, Gao P, Xiao S. From abstinence to relapse: a preliminary qualitative study of drug users in a compulsory drug rehabilitation center in Changsha, China. PLoS One. 2015;10:e0130711.

137. Van Nguyen H, Nguyen HLT, Mai HT, Le HQ, Tran BX, Hoang CD, et al. Stigmatization among methadone maintenance treatment patients in mountainous areas in northern Vietnam. Harm Reduct J. 2017;14:1.

138. Ibragimov U, Cooper HL, Haardorfer R, Dunkle KL, Zule WA, Wong FY. Stigmatization of people who inject drugs (PWID) by pharmacists in Tajikistan: sociocultural context and implications for a pharmacy-based prevention approach. Harm Reduct J. 2017;14:64.

139. James BO, Omoaregba JO, Okogbenin EO. Stigmatising attitudes towards persons with mental illness: a survey of medical students and interns from southern Nigeria. Ment IIIn. 2012;4:e8.

140. Ronzani TM, Higgins-Biddle J, Furtado EF. Stigmatization of alcohol and other drug users by primary care providers in Southeast Brazil. Soc Sci Med. 2009:69:1080-4.

141. Hayes-Larson E, Hirsch-Moverman Y, Saito S, Frederix K, Pitt B, MaamaMaime $L$, et al. Depressive symptoms and hazardous/harmful alcohol use are prevalent and correlate with stigma among TB-HIV patients in Lesotho. Int J Tuberc Lung Dis. 2017;21:34-41.

142. Papas RK, Gakinya BN, Mwaniki MM, Lee H, Kiarie SW, Martino S, et al. Rates and covariates of recent sexual and physical violence against HIV-infected outpatient drinkers in Western Kenya. AIDS Behav. 2017;21:2243-52.

143. Kerrigan D, Vazzano A, Bertoni N, Malta M, Bastos Fl. Stigma, discrimination and HIV outcomes among people living with HIV in Rio de Janeiro, Brazil: the intersection of multiple social inequalities. Glob Public Health. 2017;12: 185-99.

144. Capezza NM, Zlotnick C, Kohn R, Vicente B, Saldivia S. Perceived discrimination is a potential contributing factor to substance use and mental health problems among primary care patients in Chile. J Addict Med. 2012;6:297-303.

145. Coelho IZ, Bastos JL, Celeste RK. Moderators of the association between discrimination and alcohol consumption: findings from a representative sample of Brazilian university students. Trends Psychiatry Psychother. 2015 37:72-81.

146. Moomal H, Jackson PB, Stein DJ, Herman A, Myer L, Seedat S, et al. Perceived discrimination and mental health disorders: the South African Stress and Health study. S Afr Med J. 2009;99:383-9.

147. Ha H, Risser JMH, Ross MW, Huynh NT, Nguyen HTM. Homosexuality-related stigma and sexual risk behaviors among men who have sex with men in Hanoi, Vietnam. Arch Sex Behav. 2015;44:349-56

148. Singer M, Clair S. Syndemics and public health: reconceptualizing disease in bio-social context. Med Anthropol Q. 2003;17:423-41.

149. Rood EJJ, Mergenthaler C, Bakker MI, Redwood L, Mitchell EMH. Using 15 DHS surveys to study epidemiological correlates of TB courtesy stigma and health-seeking behaviour. Int J Tuberc Lung Dis. 2017;21:60-8.

150. Finnie RKC, Khoza LB, van den Borne B, Mabunda T, Abotchie P, Mullen PD. Factors associated with patient and health care system delay in diagnosis and treatment for TB in sub-Saharan African countries with high burdens of TB and HIV. Trop Med Int Heal. 2011;16:394-411.

151. Elafros MA, Gardiner JC, Sikazwe I, Okulicz JF, Paneth N, Chomba E, et al. Evaluating layered stigma from comorbid HIV and epilepsy among Zambian adults. eNeurologicalSci. 2018;13:56-62.

152. Clement S, Schauman O, Graham T, Maggioni F, Evans-Lacko S, Bezborodovs $\mathrm{N}$, et al. What is the impact of mental health-related stigma on help-seeking? A systematic review of quantitative and qualitative studies. Psychol Med. 2015:45:11-27.
153. Sirey JA, Bruce ML, Alexopoulos GS, Perlick DA, Raue P, Friedman SJ, et al. Perceived stigma as a predictor of treatment discontinuation in young and older outpatients with depression. Am J Psychiatry. 2001;158:479-81.

154. Sirey JA, Bruce ML, Alexopoulos GS, Perlick DA, Friedman SJ, Meyers BS. Stigma as a barrier to recovery: perceived stigma and patient-rated severity of illness as predictors of antidepressant drug adherence. Psychiatr Serv. 2001;52:1615-20.

155. Livingston JD, Boyd JE. Correlates and consequences of internalized stigma for people living with mental illness: a systematic review and meta-analysis. Soc Sci Med. 2010;71:2150-61.

156. Brain C, Sameby B, Allerby K, Quinlan P, Joas E, Lindström E, et al. Stigma, discrimination and medication adherence in schizophrenia: Results from the Swedish COAST study. Psychiatry Res. 2014;220:811-7.

157. Cluver L, Orkin M. Cumulative risk and AIDS-orphanhood: interactions of stigma, bullying and poverty on child mental health in South Africa. Soc Sci Med. 2009;69:1186-93

158. Denison JA, Koole O, Tsui S, Menten J, Torpey K, van Praag E, Mukadi YD, Colebunders R, Auld AF, Agolory S, Kaplan JE, Mulenga M, Kwesigabo GP, Wabwire-Mangen F, Bangsberg DR. Incomplete adherence among treatment-experienced adults on antiretroviral therapy in Tanzania, Uganda and Zambia. AIDS. 2015;29:361-71.

159. Deribew A, Tesfaye M, Hailmichael Y, Negussu N, Daba S, Wogi A, et al. Tuberculosis and HIV co-infection: its impact on quality of life. Health Qual Life Outcomes. 2009;7:105.

160. Duff P, Kipp W, Wild TC, Rubaale T, Okech-Ojony J. Barriers to accessing highly active antiretroviral therapy by HIV-positive women attending an antenata clinic in a regional hospital in western Uganda. J Int AIDS Soc. 2010;13:37.

161. Garrido-Hernansaiz H, Heylen E, Bharat S, Ramakrishna J, Ekstrand ML. Stigmas, symptom severity and perceived social support predict quality of life for PLHIV in urban Indian context. Health Qual Life Outcomes. 2016;14:152.

162. Greeff M, Uys LR, Wantland D, Makoae L, Chirwa M, Dlamini P, et al. Perceived HIV stigma and life satisfaction among persons living with HIV infection in five African countries: A longitudinal study. Int J Nurs Stud. 2010:47:475-86

163. Li MJ, Murray JK, Suwanteerangkul J, Wiwatanadate P. Stigma, social support, and treatment adherence among HIV-positive patients in Chiang Mai, Thailand. AIDS Educ Prev. 2014;26:471-83.

164. Li X, Li L, Wang H, Fennie KP, Chen J, Williams AB. Mediation analysis of health-related quality of life among people living with HIV infection in China. Nurs Health Sci. 2015;17:250-6.

165. Li J, Mo PKH, Kahler CW, Lau JTF, Du M, Dai Y, et al. Prevalence and associated factors of depressive and anxiety symptoms among HIV-infected men who have sex with men in China. AIDS Care. 2016:28:465-70.

166. Mekuria LA, Sprangers MAG, Prins JM, Yalew AW, Nieuwkerk PT. Healthrelated quality of life of HIV-infected adults receiving combination antiretroviral therapy in Addis Ababa. AIDS Care. 2015;27:934-45.

167. Nyamathi AM, Ekstrand M, Yadav K, Ramakrishna P, Heylen E, Carpenter C, et al. Quality of life among women living with HIV in rural India. J Assoc Nurses AIDS Care. 2017:28:575-86.

168. Peltzer K, Ramlagan S. Perceived stigma among patients receiving antiretroviral therapy: a prospective study in KwaZulu-Natal, South Africa. AIDS Care. 2011;23:60-8.

169. Sanjobo N, Frich JC, Fretheim A. Barriers and facilitators to patients' adherence to antiretroviral treatment in Zambia: a qualitative study. SAHARA J. 2008:5:136-43.

170. Subramanian T, Gupte MD, Dorairaj VS, Periannan V, Mathai AK. Psychosocial impact and quality of life of people living with HIV/AIDS in South India. AIDS Care. 2009;21:473-81.

171. Takada S, Weiser SD, Kumbakumba E, Muzoora C, Martin JN, Hunt PW, et al. The dynamic relationship between social support and HIV-related stigma in rural Uganda. Ann Behav Med. 2014;48:26-37.

172. Turan B, Stringer KL, Onono M, Bukusi EA, Weiser SD, Cohen CR, et al. Linkage to HIV care, postpartum depression, and HIV-related stigma in newly diagnosed pregnant women living with HIV in Kenya: a longitudinal observational study. BMC Pregnancy Childbirth. 2014;14:400.

173. Wu X, Chen J, Huang H, Liu Z, Li X, Wang H. Perceived stigma, medical social support and quality of life among people living with HIV/AIDS in Hunan, China. Appl Nurs Res. 2015;28:169-74.

174. Wu Y-L, Yang H-Y, Wang J, Yao H, Zhao X, Chen J, et al. Prevalence of suicidal ideation and associated factors among HIV-positive MSM in Anhui, China. Int J STD AIDS. 2015;26:496-503. 
175. Chang S-H. Cataldo JK. A systematic review of global cultural variations in knowledge, attitudes and health responses to tuberculosis stigma. Int J Tuberc Lung Dis. 2014;18:168-73.

176. Chikovore J, Hart G, Kumwenda M, Chipungu GA, Desmond N, Corbett L. Control, struggle, and emergent masculinities: a qualitative study of men's care-seeking determinants for chronic cough and tuberculosis symptoms in Blantyre. Malawi. BMC Public Health. 2014;14:1053.

177. Cramm JM, Nieboer AP. The relationship between (stigmatizing) views and lay public preferences regarding tuberculosis treatment in the Eastern Cape. South Africa. Int J Equity Health. 2011;10:2.

178. Cremers AL, De Laat MM, Kapata N, Gerrets R, Klipstein-Grobusch K, Grobusch MP. Assessing the consequences of stigma for tuberculosis patients in urban Zambia. PLoS One. 2015;10(3):e0119861.

179. Cremers AL, Gerrets R, Kapata N, Kabika A, Birnie E, Klipstein-Grobusch K, et al. Tuberculosis patients' pre-hospital delay and non-compliance with a longstanding DOT programme: a mixed methods study in urban Zambia. BMC Public Health. 2016;16:1130.

180. Juniarti N, Evans D. A qualitative review: the stigma of tuberculosis. J Clin Nurs. 2011;20:1961-70

181. Kumwenda M, Desmond N, Hart G, Choko A, Chipungu GA, Nyirenda D, et al. Treatment-seeking for tuberculosis-suggestive symptoms: a reflection on the role of human agency in the context of universal health coverage in Malawi. PLoS One. 2016;11:e0154103.

182. Mavhu W, Dauya E, Bandason T, Munyati S, Cowan FM, Hart G, et al. Chronic cough and its association with TB-HIV co-infection: factors affecting helpseeking behaviour in Harare, Zimbabwe. Trop Med Int Heal. 2010;15:574-9.

183. Miller C, Huston J, Samu L, Mfinanga S, Hopewell P, Fair E. "It makes the patient's spirit weaker": tuberculosis stigma in Dar es Salaam, Tanzania. Int J Tuberc Lung Dis. 2017;21(11):42-8.

184. Skinner D, Claassens M. It's complicated: why do tuberculosis patients not initiate or stay adherent to treatment? A qualitative study from South Africa. BMC Infect Dis. 2016;16:712.

185. Skinner D, Claassens M. Why test for tuberculosis? A qualitative study from South Africa. Public Heal Action. 2016;6:212-6.

186. Sommerland N, Wouters E, Masquillier C, Engelbrecht M, Rau A, Kigozi G, et al. Stigma as a barrier to the use of occupational health units for TB services in South Africa. Int J Tuberc Lung Dis. 2017;21(11):75-80.

187. Bifftu BB, Dachew BA, Tiruneh BT. Stigma resistance among people with schizophrenia at Amanuel Mental Specialized Hospital Addis Ababa, Ethiopia: a cross-sectional institution based study. BMC Psychiatry. 2014;14: 259.

188. Cai C. Yu L. Quality of life in patients with schizophrenia in China: relationships among demographic characteristics, psychosocial variables, and symptom severity. J Psychosoc Nurs Ment Health Serv. 2017:55:48-54.

189. Devi Thakoor JP, Dong H, Zhang $X$, Wang G, Huang $H$, Xiang $Y$, et al. Duration of untreated psychosis in Chinese and Mauritian: impact of clinical characteristics and patients' and families' perspectives on psychosis. PLoS One. 2016;11:e0157083.

190. Fresán A, Robles-García R, Madrigal E, Tovilla-Zarate C-A, Martínez-López N, Arango de Montis I. Demographic and clinical features related to perceived discrimination in schizophrenia. Psychiatry Res. 2018;262:427-30.

191. Loch AA. Stigma and higher rates of psychiatric re-hospitalization: São Paulo public mental health system. Rev Bras Psiquiatr. 2012;34:185-92.

192. Lu Y, Wang X. Correlation between insight and internalized stigma in patients with schizophrenia. Shanghai Arch Psychiatry. 2012;24:91-8.

193. Milačić Vidojević I, Dragojević N, Tošković O. Experienced and anticipated discrimination among people with major depressive disorder in Serbia. Int J Soc Psychiatry. 2015;61:638-44

194. Wang $X Q$, Petrini MA, Morisky DE. Predictors of quality of life among Chinese people with schizophrenia. Nurs Health Sci. 2017;19:142-8.

195. Alkhamees H, Selai C, Shorvonm S. Which factors have the greatest effect on quality of life among patients with epilepsy in Saudi Arabia? Epilepsia. 2013:54:114-5.

196. Bhalla D, Chea K, Hun C, Vannareth M, Huc P, Chan S, et al. Populationbased study of epilepsy in Cambodia associated factors, measures of impact, stigma, quality of life, knowledge-attitude-practice, and treatment gap. PLoS One. 2012;7:e46296.

197. Hamid H, Kasasbeh AS, Suleiman MJ, Cong X, Liu H, Mohiuddin S, et al. Neuropsychiatric symptoms, seizure severity, employment, and quality of life of Jordanians with epilepsy. Epilepsy Behav. 2013;27:272-5.
198. Komolafe MA, Sunmonu TA, Fabusiwa F, Komolafe EO, Afolabi O, Kett M, Groce N. Women's perspectives on epilepsy and its sociocultural impact in south western Nigeria. African J Neurol Sci. 2011;30:77320.

199. Kumari P, Ram D, Haque Nizamie S, Goyal N. Stigma and quality of life in individuals with epilepsy: a preliminary report. Epilepsy Behav. 2009; 15:358-61.

200. Lopez V, Barragan EP, Hernandez MH. Quality life in pediatric patients with epilepsy in Mexico. Epilepsia. 2009;50:404-5.

201. Nagarathnam M, Vengamma B, Shalini B, Latheef S. Stigma and polytherapy: predictors of quality of life in patients with epilepsy from South India. Ann Indian Acad Neurol. 2017;20:233-41.

202. Nehra A, Singla S, Bajpai S, Malviya S, Padma V, Tripathi M. Inverse relationship between stigma and quality of life in India: Is epilepsy a disabling neurological condition? Epilepsy Behav. 2014;39:116-25.

203. Saadi A, Patenaude B, Nirola DK, Deki S, Tshering L, Clark S, et al. Quality of life in epilepsy in Bhutan. Seizure. 2016;39:44-8.

204. Tegegne MT, Mossie TB, Awoke AA, Assaye AM, Gebrie BT, Eshetu DA. Depression and anxiety disorder among epileptic people at Amanuel Specialized Mental Hospital, Addis Ababa, Ethiopia. BMC Psychiatry. 2015;15:210.

205. Tsegabrhan H, Negash A, Tesfay K, Abera M. Co-morbidity of depression and epilepsy in Jimma University specialized hospital, Southwest Ethiopia. Neurol India. 2014:62:649-55.

206. Viteva E. Stigmatization of patients with epilepsy: a review of the current problem and assessment of the perceived stigma in Bulgarian patients. Epilepsy Behav. 2012;25:239-43.

207. Viteva E. Impact of stigma on the quality of life of patients with refractory epilepsy. Seizure. 2013;22:64-9.

208. Brittain K, Remien RH, Phillips T, Zerbe A, Abrams EJ, Myer L, et al. Factors associated with alcohol use prior to and during pregnancy among HIVinfected pregnant women in Cape Town, South Africa. Drug Alcohol Depend. 2017:173:69-77.

209. Budhwani H, Hearld KR, Milner AN, McGlaughlin E, Charow R, RodriguezLauzurique RM, et al. Transgender women's drug use in the Dominican Republic. Transgender Heal. 2017;2:188-94.

210. Culbert GJ, Earnshaw VA, Wulanyani NMS, Wegman MP, Waluyo A Altice FL. Correlates and experiences of HIV stigma in prisoners living with HIV in Indonesia: a mixed-method analysis. J Assoc Nurses AIDS Care. 2015;26:743-57

211. Fan $W, L u R, W u G$, Yousuf MA, Feng $L$, Li X, et al. Alcohol drinking and HIVrelated risk among men who have sex with men in Chongqing, China. Alcohol. 2016:50:1-7.

212. Go VF, Latkin C, Le Minh N, Frangakis C, Ha TV, Sripaipan T, et al. Variations in the role of social support on disclosure among newly diagnosed HIVinfected people who inject drugs in Vietnam. AIDS Behav. 2016;20:155-64

213. Goldstone D, Bantjes J. Mental health care providers' perceptions of the barriers to suicide prevention amongst people with substance use disorders in South Africa: a qualitative study. Int J Ment Health Syst. 2017;11:46.

214. Greene MC, Zhang J, Li J, Desai M, Kershaw T. Mental health and social support among HIV-positive injection drug users and their caregivers in China. AIDS Behav. 2013;17:1775-84.

215. Heath AJ, Kerr T, Ti L, Kaplan K, Suwannawong P, Wood E, et al. Healthcare avoidance by people who inject drugs in Bangkok, Thailand. J Public Health. 2016;38:e301-8

216. Johannson A, Vorobjov S, Heimer R, Dovidio JF, Uusküla A. The role of internalized stigma in the disclosure of injecting drug use among people who inject drugs and self-report as HIV-positive in Kohtla-Järve, Estonia. AIDS Behav. 2017;21:1034-43.

217. Khuat OTH, Morrow M, Nguyen TNN, Armstrong G. Social context, diversity and risk among women who inject drugs in Vietnam: descriptive findings from a cross-sectional survey. Harm Reduct J. 2015;12:35.

218. Krawczyk N, Filho CLV, Bastos Fl. The interplay between drug-use behaviors, settings, and access to care: a qualitative study exploring attitudes and experiences of crack cocaine users in Rio de Janeiro and Sao Paulo, Brazil. Harm Reduct J. 2015;12:24

219. Lembke A. Zhang N. A qualitative study of treatment-seeking heroin users in contemporary China. Addict Sci Clin Pract. 2015;10:23.

220. Liao M, Kang D, Tao X, Bouey JH, Aliyu MH, Qian Y, et al. Alcohol use, stigmatizing/discriminatory attitudes, and HIV high-risk sexual behaviors among men who have sex with men in China. Biomed Res Int. 2014;2014: 143738 . 
221. Lozano-Verduzco I, Romero-Mendoza M, Marin-Navarrete R. Violence narratives of Mexican women treated in mutual-aid residential centers for addiction treatment. Subst Abuse Treat Prev Policy. 2016;11:39.

222. Luo T, Wang J, Li Y, Wang X, Tan L, Deng Q, et al. Stigmatization of people with drug dependence in China: a community-based study in Hunan province. Drug Alcohol Depend. 2014;134:285-9.

223. Mattoo SK, Sarkar S, Nebhinani N, Gupta S, Parakh P, Basu D. How do Indian substance users perceive stigma towards substance use vis-a-vis their family members? J Ethn Subst Abuse. 2015;14:223-31.

224. Myers B. Barriers to alcohol and other drug treatment use among Black African and coloured South Africans. BMC Health Serv Res. 2013;13:177.

225. Otiashvili D, Kirtadze I, O'Grady KE, Zule W, Krupitsky E, Wechsberg WM, et al. Access to treatment for substance-using women in the Republic of Georgia: socio-cultural and structural barriers. Int J Drug Policy. 2013;24:566-72.

226. Peacock E, Andrinopoulos K, Hembling J. Binge drinking among men who have sex with men and transgender women in San Salvador: correlates and sexual health implications. J Urban Health. 2015;92:701-16.

227. Rathod SD, Nadkarni A, Bhana A, Shidhaye R. Epidemiological features of alcohol use in rural India: a population-based cross-sectional study. BMJ Open. 2015;5:e009802.

228. Sharma V, Sarna A, Tun W, Saraswati LR, Thior I, Madan I, et al. Women and substance use: a qualitative study on sexual and reproductive health of women who use drugs in Delhi, India. BMJ Open. 2017:7:e018530.

229. Spooner C, Saktiawati AMI, Lazuardi E, Worth H, Subronto YW, Padmawati RS. Impacts of stigma on HIV risk for women who inject drugs in Java: a qualitative study. Int J Drug Policy. 2015;26:1244-50.

230. Asia Catalyst. Survey of Chinese Transgender Female Sex Workers. 2015. http://zh.asiacatalyst.org/blog/2015/01/15/new-report-survey-of-chinesetransgender-female-sex-workers/. Accessed 19 Dec 2018

231. Badgett MVL. The Economic Cost of Stigma and the Exclusion of LGBT People: A Case Study of India. 2014. http://documents.worldbank.org/ curated/en/527261468035379692/pdf/ 940400WPOBox380usion0ofOLGBTOPeople.pdf. Accessed 4 Feb 2018

232. UNDP, USAID. Being LGBT in Asia: The Vietnam Country Report. 2014. https://www.usaid.gov/sites/default/files/documents/1861/Being_LGBT_in_ Asia Viet Nam report ENG.pdf. Accessed 19 Dec 2018.

233. UNDP, USAID. Being LGBT in Asia: Nepal Country Report. 2014. https://www usaid.gov/documents/1861/being-lgbt-asia-nepal-country-report. Accessed 11 Dec 2018.

234. Ahmed A, Stewart DE, Teng L, Wahoush O, Gagnon AJ. Experiences of immigrant new mothers with symptoms of depression. Arch Womens Ment Health. 2008;11:295-303.

235. Wu MC, Kviz FJ, Miller AM. Identifying individual and contextual barriers to seeking mental health services among Korean American immigrant women. Issues Ment Health Nurs. 2009;30:78-85.

236. Conrad MM, Pacquiao DF. Manifestation, attribution, and coping with depression among Asian Indians from the perspectives of health care practitioners. J Transcult Nurs. 2005;16:32-40.

237. Pulerwitz J, Michaelis AP, Lippman SA, Chinaglia M, Díaz J. HIV-related stigma, service utilization, and status disclosure among truck drivers crossing the Southern borders in Brazil. AIDS Care. 2008;20:764-70.

238. Enriquez M, Kelly PJ, Witt J, Rodriguez L, Lopez N, Smueles J, et al. Silence is not golden: invisible Latinas living with HIV in the Midwest. J Immigr Minor Heal. 2010;12:932-9.

239. Mak WWS, Cheung RYM. Self-stigma among concealable minorities in Hong Kong: Conceptualization and unified measurement. Am J Orthopsychiatry. 2010;80:267-81.

240. Wynaden D, Chapman R, Orb A, McGowan S, Zeeman Z, Yeak S. Factors that influence Asian communities' access to mental health care. Int J Ment Health Nurs. 2005;14:88-95.

241. Abarca Tomás B, Pell C, Bueno Cavanillas A, Guillén Solvas J, Pool R, Roura M. Tuberculosis in migrant populations. A systematic review of the qualitative literature. PLoS One. 2013;8:e82440.
242. MacLeod-Bluver C. "I Didn't Feel Like Living": The Prevalence, Perceptions, and Prevention of HIV/AIDS Among Tibetan Refugees in Kathmandu. Independent Study Project (ISP) Collection. 2009. http://digitalcollections.sit. edu/isp collection/807. Accessed 4 Feb 2018.

243. Popinchalk A. Refugees, HIV/AIDS and Access to Medical Care: A Case Study of Cairo, Egypt. 2009. http://digitalcommons.macalester.edu/geography_ honors. Accessed 4 Feb 2018.

244. Wirtz AL, Glass N, Pham K, Aberra A, Rubenstein LS, Singh S, et al. Development of a screening tool to identify female survivors of genderbased violence in a humanitarian setting: qualitative evidence from research among refugees in Ethiopia. Confl Health. 2013;7:13.
Ready to submit your research? Choose BMC and benefit from:

- fast, convenient online submission

- thorough peer review by experienced researchers in your field

- rapid publication on acceptance

- support for research data, including large and complex data types

- gold Open Access which fosters wider collaboration and increased citations

- maximum visibility for your research: over $100 \mathrm{M}$ website views per year

At $\mathrm{BMC}$, research is always in progress.

Learn more biomedcentral.com/submissions 